\title{
OPEN Optimizing the plasma oxidation of aluminum gate electrodes for ultrathin gate oxides in organic transistors
}

\author{
Michael Geiger ${ }^{1}$, Marion Hagel ${ }^{1}$, Thomas Reindl ${ }^{1}$, Jürgen Weis ${ }^{1}$, R. Thomas Weitz ${ }^{2,3}$, \\ Helena Solodenko ${ }^{4}$, Guido Schmitz ${ }^{4}$, Ute Zschieschang ${ }^{1}$, Hagen Klauk ${ }^{1}$ \& \\ Rachana Acharya ${ }^{1,4} \bowtie$
}

A critical requirement for the application of organic thin-film transistors (TFTs) in mobile or wearable applications is low-voltage operation, which can be achieved by employing ultrathin, high-capacitance gate dielectrics. One option is a hybrid dielectric composed of a thin film of aluminum oxide and a molecular self-assembled monolayer in which the aluminum oxide is formed by exposure of the surface of the aluminum gate electrode to a radio-frequency-generated oxygen plasma. This work investigates how the properties of such dielectrics are affected by the plasma power and the duration of the plasma exposure. For various combinations of plasma power and duration, the thickness and the capacitance of the dielectrics, the leakage-current density through the dielectrics, and the current-voltage characteristics of organic TFTs in which these dielectrics serve as the gate insulator have been evaluated. The influence of the plasma parameters on the surface properties of the dielectrics, the thin-film morphology of the vacuum-deposited organic-semiconductor films, and the resulting TFT characteristics has also been investigated.

Organic thin-film transistors (TFTs) are being developed for flexible electronics applications, such as rollable or foldable active-matrix displays and conformable sensors ${ }^{1-5}$. To ensure the safe handling and portable nature of these systems, they will typically be powered by small batteries or solar cells and will thus be operating at low voltages of about 2 to $3 \mathrm{~V}$. To enable organic TFTs to operate with low voltages, the gate dielectric should have a large unit-area capacitance. Examples of gate dielectrics suitable for low-voltage organic TFTs include thin insulating polymers ${ }^{6,7}$, high-permittivity insulating metal oxides ${ }^{8,9}$, self-assembled nanodielectrics ${ }^{10,11}$, and ultrathin hybrid dielectrics composed of a thin metal oxide in combination with a molecular self-assembled monolayer $(\mathrm{SAM})^{12,13}$. The thickness of these dielectrics must be sufficiently small to provide a large unit-area capacitance and thereby low-voltage TFT operation ${ }^{14-17}$, but sufficiently large to suppress undesirable charge leakage and thus allow for low-power circuit and system operation ${ }^{18-20}$. In addition, the dielectrics should be sufficiently robust to allow the TFTs to be fabricated on unconventional and potentially rough substrates, such as plastics and paper ${ }^{21-23}$.

This work focuses on ultrathin hybrid gate dielectrics. The first component of these dielectrics is a thin metal oxide that can be produced by atomic layer deposition ${ }^{8,24,25}$, anodic oxidation ${ }^{26-28}$, UV/ozone-assisted oxidation $^{29-31}$, or plasma-assisted oxidation of the surface of the gate electrode ${ }^{13}$. Among the advantages of the plasma-oxidation process are the fact that it does not require electrical contact to the gate metal during the oxidation process $^{32}$ (which greatly simplifies the fabrication process), that the oxide is formed only where needed for the TFTs (which eliminates the need for subtractive patterning to open vias for interconnects ${ }^{22}$ ) and that the high quality of the native interface between the gate metal and the gate oxide minimizes the hysteresis in the current-voltage characteristics and the subthreshold swing of the TFTs ${ }^{33,34}$. The most popular material combinations for the gate metal and the gate oxide are aluminum/aluminum oxide ${ }^{15,35}$ and titanium/titanium oxide ${ }^{14,27}$.

The second component of these hybrid dielectrics is a SAM of organic molecules that are composed of an anchor group to facilitate chemisorption on the metal-oxide surface and an aliphatic tail to facilitate the

\footnotetext{
${ }^{1}$ Max Planck Institute for Solid State Research, Stuttgart, Germany. ${ }^{2}$ The 1st Physical Institute, University of Göttingen, Göttingen, Germany. ${ }^{3}$ Faculty of Physics, Ludwig-Maximilians-University, München, Germany. ${ }^{4}$ Institute of Materials Science, University of Stuttgart, Stuttgart, Germany. ${ }^{\varpi}$ email: M.Geiger@ fkf.mpg.de; R.Acharya@fkf.mpg.de
} 
(a)

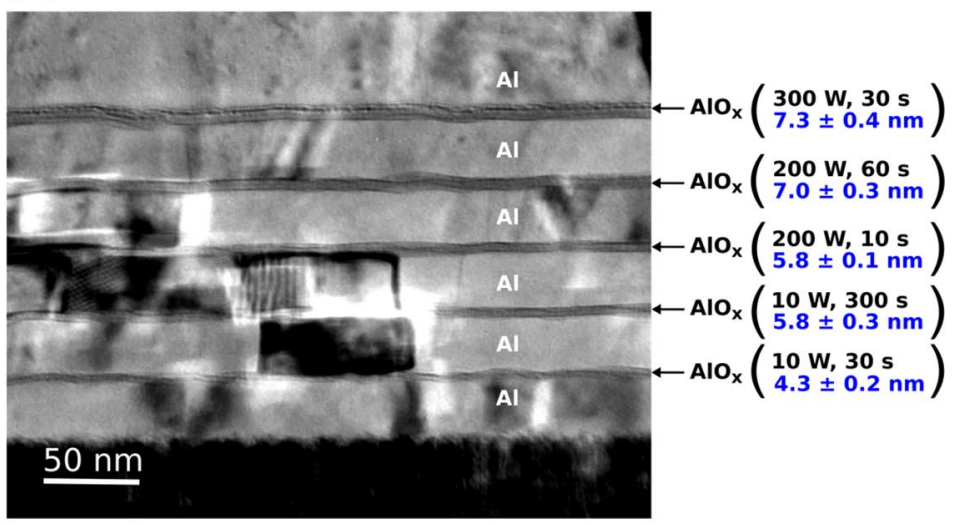

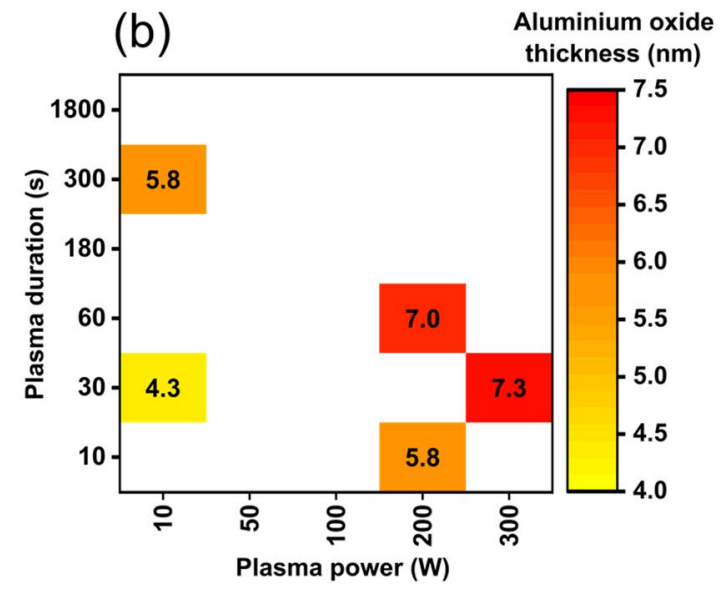

Figure 1. Thickness of plasma-grown aluminum oxide films. (a) Cross-sectional TEM image indicating the thicknesses of five $\mathrm{AlO}_{\mathrm{x}}$ films produced sequentially by the plasma-assisted surface oxidation of aluminum using five different combinations of plasma power and plasma duration. (b) Summary of the results.

self-assembly of a well-ordered molecular monolayer ${ }^{36}$. The preferred anchor group for chemisorption on aluminum oxide is the phosphonic acid ${ }^{37}$, while the aliphatic tail can be an alkyl or fluoroalkyl chain ${ }^{25,38-41}$. The effects of the properties of the SAM-forming molecules, such as the alkyl or fluoroalkyl chain length ${ }^{31,42-44}$, and the details of the SAM-formation process have been investigated in great detail in the past ${ }^{45-48}$. One result of these studies is that the best TFT performance is often obtained with a medium-chain-length alkylphosphonic acid, such as $n$-tetradecylphosphonic acid, processed from solution.

In this work, we focused on the metal-oxide component of the hybrid dielectric. We prepared thin films of aluminum oxide $\left(\mathrm{AlO}_{\mathrm{x}}\right)$ by exposing the surface of vacuum-deposited aluminum films to a capacitively coupled radio-frequency $(13.56 \mathrm{MHz})$ plasma in pure, low-pressure oxygen and investigated the extent to which the properties of the resulting $\mathrm{AlO}_{\mathrm{x}}$ films can be tuned by adjusting two of the parameters of the plasma-oxidation process, namely the plasma power and the duration of the plasma exposure. We varied the plasma power from 10 to $300 \mathrm{~W}$ and the plasma duration from 10 to $1800 \mathrm{~s}$ and studied how this affects the properties of the $\mathrm{AlO}_{\mathrm{x}}$ films and those of organic TFTs in which these $\mathrm{AlO}_{\mathrm{x}}$ films serve either as the gate dielectric or as the first component of a hybrid $\mathrm{AlO}_{\mathrm{x}} / \mathrm{SAM}$ gate dielectric. The thickness of the plasma-grown $\mathrm{AlO}_{\mathrm{x}}$ films was determined by transmission electron microscopy (TEM). For both the bare- $\mathrm{AlO}_{\mathrm{x}}$ and the hybrid $\mathrm{AlO}_{\mathrm{x}} / \mathrm{SAM}$ dielectrics, we measured the unit-area capacitance, the leakage-current density, the surface properties and the current-voltage characteristics of organic TFTs fabricated in the inverted staggered (bottom-gate, top-contact) architecture using the vacuum-deposited small-molecule semiconductor dinaphtho[2,3-b:2',3'-f]thieno[3,2-b]thiophene $(\text { DNTT })^{49-51}$ and analyzed the effects of the plasma parameters on these material and device characteristics.

\section{Results and discussion}

Thickness of plasma-grown $\mathrm{AlO}_{\mathbf{x}}$ films. Figure 1a shows a cross-sectional TEM image of a specimen prepared on a silicon substrate by repeating the deposition of 30-nm-thick aluminum and the plasma-assisted oxidation of the aluminum surface five times, each time with a different combination of plasma power and plasma duration. During each transfer of the substrate from the metal-deposition system to the plasma system, the aluminum surface was necessarily exposed to ambient air, causing the spontaneous formation of a native oxide film with a thickness of approximately $3 \mathrm{~nm}$ on the aluminum surface ${ }^{52}$. The TEM image indicates that after the plasma-assisted oxidation, the aluminum oxide films have a thickness of approximately 4.3 to $7.3 \mathrm{~nm}$, depending on the plasma parameters. (The method of extracting the thickness of the $\mathrm{AlO}_{\mathrm{x}}$ films from the TEM image is detailed in Fig. S1).

The lower limit of this thickness range $(4.3 \mathrm{~nm})$ is thus larger by approximately $1.3 \mathrm{~nm}$ than the thickness of the native oxide. Although this increase in the oxide thickness produced by the plasma process is quite small, it is of critical importance for the proper operation of organic TFTs in which these dielectrics are used as the gate insulator. Figure S2 shows the measured transfer characteristics of DNTT TFTs fabricated using bare- $\mathrm{AlO}_{\mathrm{x}}$ and hybrid $\mathrm{AlO}_{\mathrm{x}}$ /SAM gate dielectrics based on native aluminum oxide (obtained without plasma process), and as can be seen, these TFTs either do not show a field effect (bare $\mathrm{AlO}_{\mathrm{x}}$ ) or suffer from prohibitively large gate currents (hybrid $\mathrm{AlO}_{\mathrm{x}} / \mathrm{SAM}$ dielectric).

The relation between the plasma parameters and the thickness of the plasma-grown $\mathrm{AlO}_{\mathrm{x}}$ films extracted from the TEM image is illustrated in Fig. 1b. As expected, both a larger plasma power (by virtue of a higher kinetic energy of the oxygen radicals impinging on the oxide surface) and a longer plasma duration (by virtue of a larger number of incident radicals) result in thicker $\mathrm{AlO}_{\mathrm{x}}$ films.

Electrical properties of plasma-grown $\mathrm{AlO}_{\mathrm{x}}$ dielectrics. To investigate how the electrical properties of plasma-grown $\mathrm{AlO}_{\mathrm{x}}$ dielectrics and of hybrid $\mathrm{AlO}_{\mathrm{x}} / \mathrm{SAM}$ dielectrics are affected by the plasma parameters, we fabricated metal-insulator-metal capacitors and bottom-gate, top-contact DNTT TFTs with dielectrics prepared using fifteen different combinations of plasma power (ranging from 10 to $300 \mathrm{~W}$ ) and plasma duration 

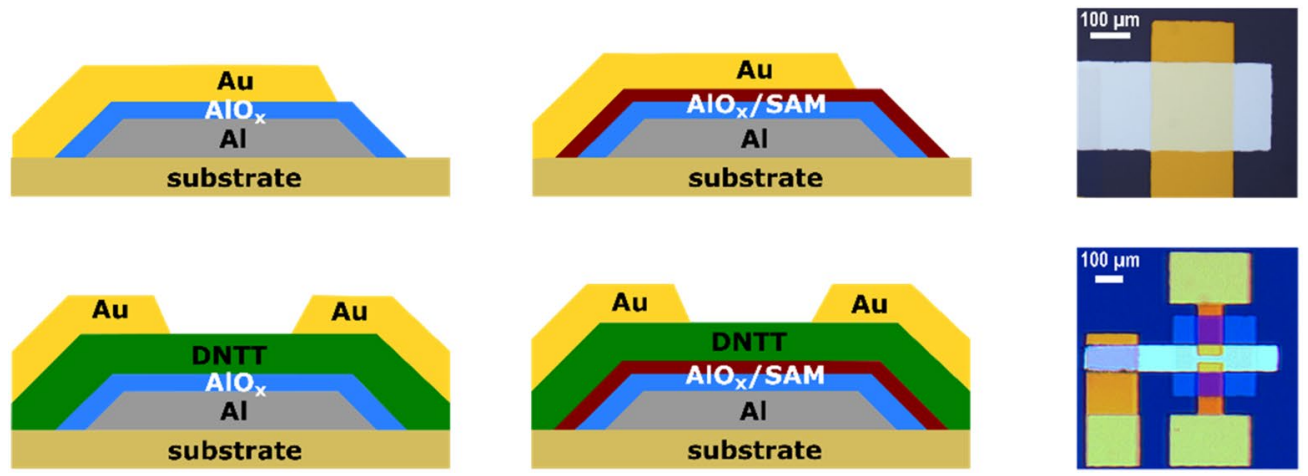

Figure 2. Schematic cross sections and photographs of metal-insulator-metal capacitors and bottom-gate, topcontact TFTs in which the insulator or gate dielectric is either a film of plasma-grown $\mathrm{AlO}_{\mathrm{x}}$ or a combination of plasma-grown $\mathrm{AlO}_{\mathrm{x}}$ and an $n$-tetradecylphosphonic acid SAM. Also shown are the chemical structure of $n$-tetradecylphosphonic acid and of the organic semiconductor dinaphtho[2,3-b:2', $3^{\prime}$-f] thieno[3,2-b]thiophene (DNTT).

(ranging from 10 to $1800 \mathrm{~s}$ ). The devices were fabricated on silicon substrates coated with 100-nm-thick silicon dioxide. For the bottom electrode of the capacitors and the gate electrode of the TFTs, aluminum with a thickness of $30 \mathrm{~nm}$ and a root-mean-square surface roughness of less than $1 \mathrm{~nm}$ (measured by $\mathrm{AFM}^{53}$ ) was deposited by vacuum evaporation. $\mathrm{AlO}_{\mathrm{x}}$ was produced by plasma oxidation, SAMs of $n$-tetradecylphosphonic acid were formed from solution, and DNTT was deposited by vacuum sublimation. For the top electrode of the capacitors and the source/drain contacts of the TFTs, gold was deposited by vacuum evaporation. Schematic cross sections and photographs of the capacitors and TFTs and the chemical structures of $n$-tetradecylphosphonic acid and DNTT are shown in Fig. 2.

The measured unit-area capacitance of the capacitors with a bare- $\mathrm{AlO}_{\mathrm{x}}$ dielectric is plotted as a function of the plasma power and the plasma duration in Fig. 3a. Depending on these parameters, the unit-area capacitance varies from 1 to $1.6 \mu \mathrm{F} / \mathrm{cm}^{2}$, with the general trend of higher power and longer duration producing $\mathrm{AlO}_{\mathrm{x}}$ films with smaller capacitance. In Fig. 3b, we plot the unit-area capacitance measured for each of the five plasma-parameter combinations for which the $\mathrm{AlO}_{\mathrm{x}}$ thickness was determined by TEM (Fig. 1) as a function of the inverse of that thickness. The error bars reflect the accuracy of the method by which the oxide thickness was extracted from the TEM image (see Fig. S1). By fitting the measurement data with the theoretical relation between the unit-area capacitance $\mathrm{C}_{\mathrm{ox}}$ and the oxide thickness $\mathrm{t}_{\mathrm{ox}}$ :

$$
\mathrm{C}_{\mathrm{ox}}=\varepsilon_{0} \varepsilon_{\mathrm{ox}} \frac{1}{\mathrm{t}_{\mathrm{ox}}}
$$

(where $\varepsilon_{0}$ is the vacuum permittivity and $\varepsilon_{\mathrm{ox}}$ the relative permittivity of the plasma-grown oxide) and forcing the linear fit through the origin $\left(1 / \mathrm{t}_{\mathrm{ox}}=0 ; \mathrm{C}_{\mathrm{ox}}=0\right)$, we obtain a value of $8 \pm 0.2$ for the relative permittivity of the plasma-grown $\mathrm{AlO}_{\mathrm{x}}$ films. This result is in good agreement with the relative permittivity reported in the literature for aluminum oxide films produced by various methods ${ }^{54-56}$.

We note that a more elaborate analysis of the relation between the oxide thickness and the oxide capacitance would have included measurements of the oxide thickness for all fifteen combinations of plasma power and plasma duration shown in Fig. 3a, as opposed to selecting only five of these fifteen combinations for the TEM measurements. However, as this was not possible, we deliberately selected for the TEM analysis five plasmaparameter combinations covering both the extremes and the center of the range of thicknesses and capacitances as much as possible.

Closer inspection of Fig. 3a reveals that the influence of the plasma duration on the capacitance is relatively small, as long as the plasma power is at least $50 \mathrm{~W}$ and the duration is at least $30 \mathrm{~s}$. For example, for a plasma power of $200 \mathrm{~W}$, a unit-area capacitance of $1 \mu \mathrm{F} / \mathrm{cm}^{2}$ is obtained for a plasma duration of one minute and for a plasma duration of half an hour. Combined with the TEM results (Fig. 1), this suggests that the thickness of the plasma-grown $\mathrm{AlO}_{\mathrm{x}}$ films saturates at a value of approximately $7 \mathrm{~nm}$ after a plasma duration of 30 to $60 \mathrm{~s}$, provided the plasma power is at least $50 \mathrm{~W}$. According to the Cabrera-Mott model ${ }^{57}$, this self-limiting oxide-growth behavior results from the low electronic conductivity of aluminum oxide and the small diffusivity of oxygen in aluminum oxide, which prevents oxygen from reaching the metal surface once the oxide thickness has reached a certain value determined mainly by the plasma power ${ }^{57-59}$.

Compared with the dependence of the capacitance on the plasma duration, its dependence on the plasma power appears to be more monotonic, but overall, the range over which the capacitance of the plasma-grown $\mathrm{AlO}_{\mathrm{x}}$ can be tuned is nevertheless quite small (less than a factor of two). One benefit of this small range of accessible capacitances is that it renders the fabrication process more robust by suppressing the effects of unintended process-parameter variations on the resulting TFT characteristics.

In addition to the capacitance, we also measured the current-voltage characteristics of the capacitors to analyze the influence of the plasma power and duration on the leakage-current density through the dielectrics. The results for the capacitors with a bare- $\mathrm{AlO}_{\mathrm{x}}$ dielectric are summarized in Fig. 4a. The general trend is similar 


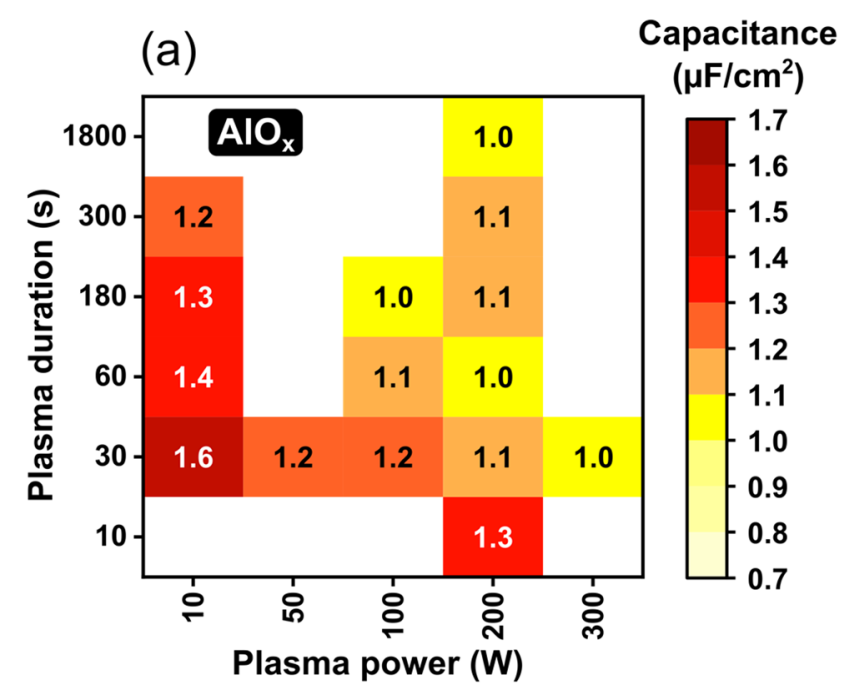

(b)
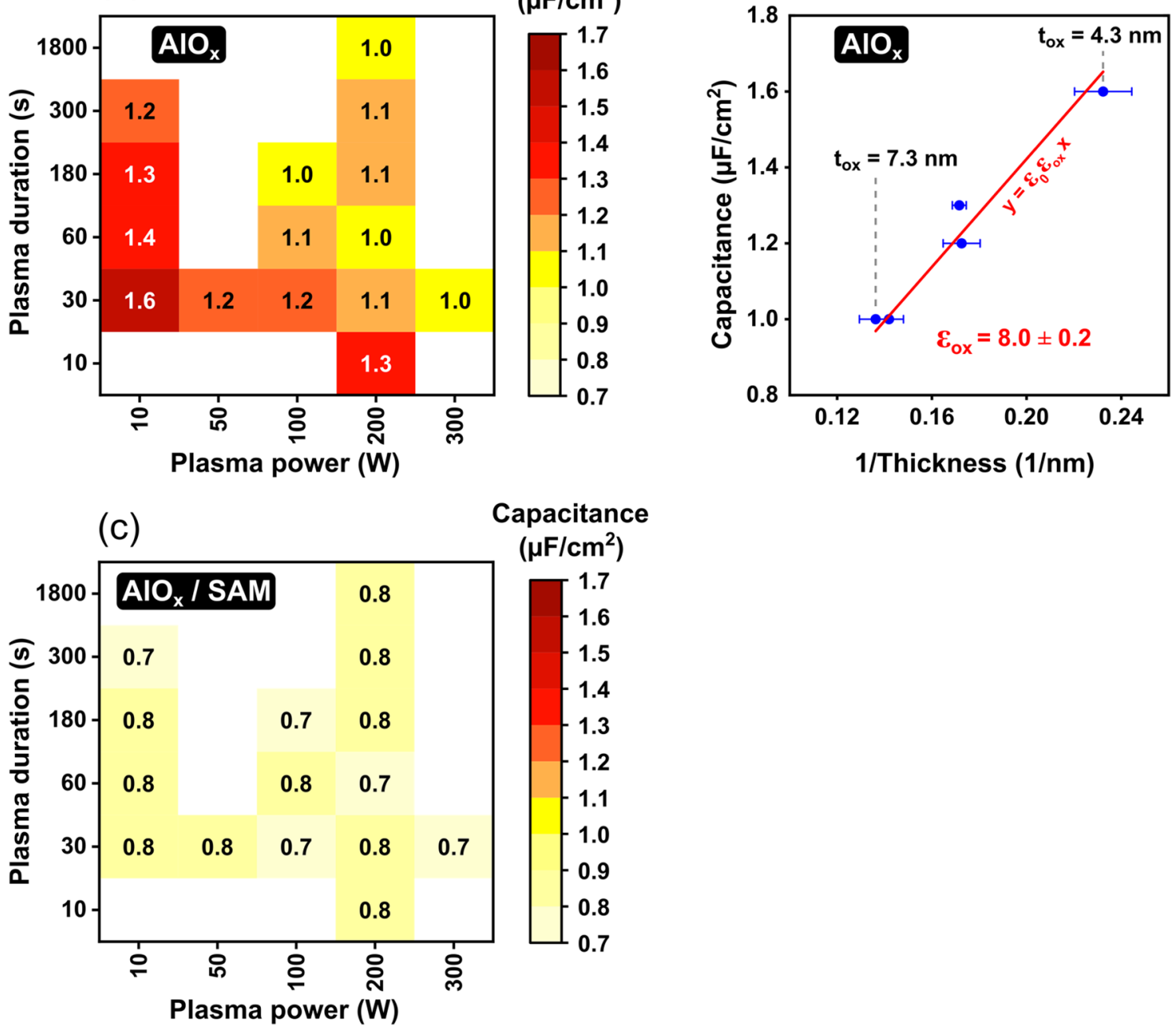

Figure 3. Capacitance of plasma-grown $\mathrm{AlO}_{\mathrm{x}}$ and hybrid $\mathrm{AlO}_{\mathrm{x}} / \mathrm{SAM}$ dielectrics. (a) Measured unit-area capacitance of capacitors with a bare- $\mathrm{AlO}_{\mathrm{x}}$ dielectric as a function of plasma power and plasma duration. (b) Unit-area capacitance of bare- $\mathrm{AlO}_{\mathrm{x}}$ dielectrics plotted as a function of the inverse of the $\mathrm{AlO}_{\mathrm{x}}$ thickness determined by TEM (Fig. 1) to calculate the relative permittivity of the plasma-grown $\mathrm{AlO}_{\mathrm{x}}$. The red line is a linear fit of Eq. (1) that was forced to pass through the origin $\left(1 / t_{o x}=0 ; C_{o x}=0\right)$. (c) Measured unit-area capacitance of capacitors with a hybrid $\mathrm{AlO}_{\mathrm{x}} / \mathrm{SAM}$ dielectric as a function of plasma power and plasma duration.

to the one seen for the capacitance in Fig. $3 \mathrm{a}$ and is consistent with the TEM results: a higher plasma power and a longer plasma duration lead to thicker $\mathrm{AlO}_{\mathrm{x}}$ films characterized by smaller leakage-current densities.

When the plasma power is smaller than about 50 to $100 \mathrm{~W}$ and the plasma duration is shorter than about 30 to $60 \mathrm{~s}$, the leakage-current density through the bare- $\mathrm{AlO}_{\mathrm{x}}$ films exceeds $10^{-4} \mathrm{~A} / \mathrm{cm}^{2}$ at $\pm 3 \mathrm{~V}$. On the other hand, for a plasma power of $200 \mathrm{~W}$ and a plasma duration of $60 \mathrm{~s}$, the current density through the bare- $\mathrm{AlO}_{\mathrm{x}}$ dielectrics is below $10^{-5} \mathrm{~A} / \mathrm{cm}^{2}$ at $\pm 3 \mathrm{~V}$. Figure $4 \mathrm{a}$ also shows that it is not possible to produce bare- $\mathrm{AlO}_{\mathrm{x}}$ dielectrics by plasma oxidation that provide leakage-current densities significantly below $10^{-6} \mathrm{~A} / \mathrm{cm}^{2}$ at $\pm 3 \mathrm{~V}$.

Electrical properties of hybrid $\mathrm{AIO}_{\mathrm{x}} / \mathrm{SAM}$ dielectrics. Although it is possible to use the bare, plasmagrown $\mathrm{AlO}_{\mathrm{x}}$ films discussed above as the gate dielectric for organic TFTs ${ }^{40,60,61}$, the often-preferred option is a hybrid gate dielectric in which the $\mathrm{AlO}_{\mathrm{x}}$ is complemented by a phosphonic-acid SAM. This has a number of advantages, including a smaller density of interface trap states ${ }^{62}$, a smaller leakage-current density ${ }^{40}$, an improved bias-stress stability due to the expulsion of water from the semiconductor-dielectric interface ${ }^{63}$, the suppression of Fröhlich polarons due to the low permittivity of the organic SAM ${ }^{64}$, the possibility to tune the threshold voltage of the TFTs ${ }^{15,25,38,65,66}$, and the possibility to tune the surface energy of the dielectric.

In Fig. 3c, the unit-area capacitance of the capacitors with a hybrid $\mathrm{AlO}_{\mathrm{x}} / \mathrm{SAM}$ dielectric is plotted as a function of the plasma power and plasma duration. Due to the additional contribution of the SAM, the capacitance of the hybrid $\mathrm{AlO}_{\mathrm{x}} / \mathrm{SAM}$ dielectric $\left(0.7-0.8 \mu \mathrm{F} / \mathrm{cm}^{2}\right)$ is smaller than that of the bare- $\mathrm{AlO}_{\mathrm{x}}$ dielectric $(1-1.6 \mu \mathrm{F} /$ $\mathrm{cm}^{2}$ ) and shows a notably smaller dependence on the plasma power and duration. From the measured unit-area capacitances of the bare- $\mathrm{AlO}_{\mathrm{x}}$ and the hybrid $\mathrm{AlO}_{\mathrm{x}} / \mathrm{SAM}$ dielectrics, the unit-area capacitance of the SAM can 

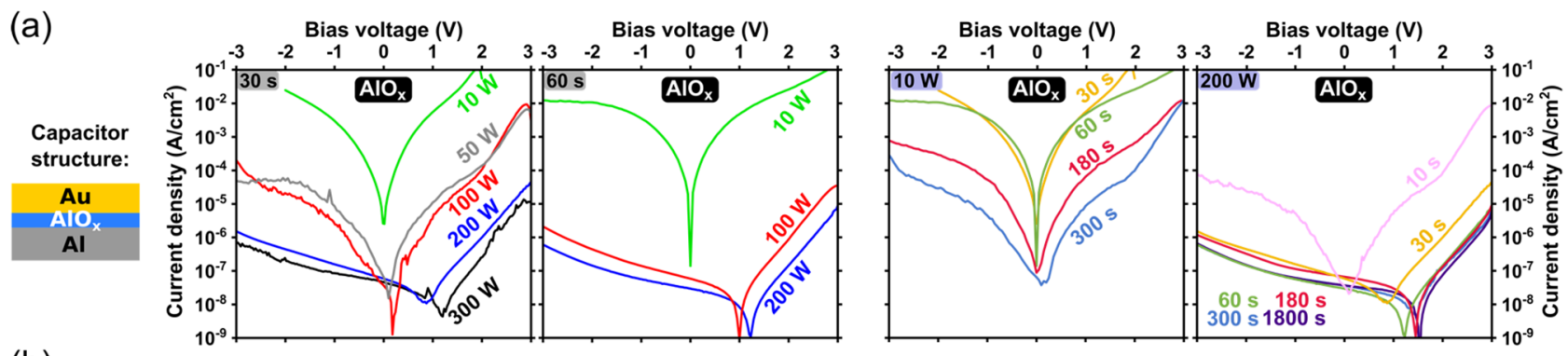

(b)
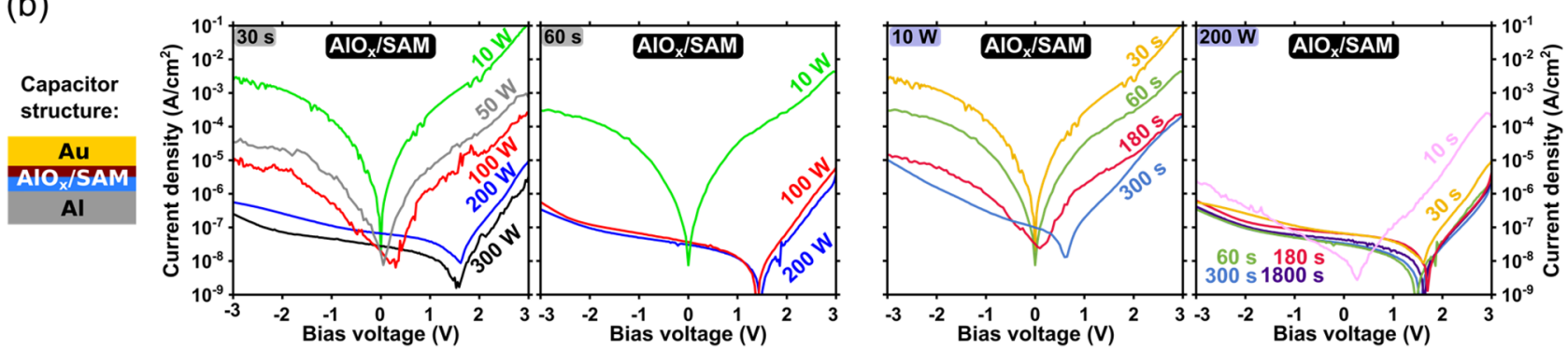

Figure 4. Current density measured as a function of applied voltage through capacitors with a bare- $\mathrm{AlO}_{\mathrm{x}}$ dielectric (a) and a hybrid $\mathrm{AlO}_{\mathrm{x}} / \mathrm{SAM}$ dielectric $(\mathbf{b})$ for various combinations of plasma power and plasma duration.

be estimated using the equation $1 / \mathrm{C}_{\text {total }}=1 / \mathrm{C}_{\mathrm{ox}}+1 / \mathrm{C}_{\mathrm{SAM}}$ (where $\mathrm{C}_{\text {total }}, \mathrm{C}_{\mathrm{ox}}$ and $\mathrm{C}_{\mathrm{SAM}}$ are the unit-area capacitances of the hybrid $\mathrm{AlO}_{\mathrm{x}} / \mathrm{SAM}$ dielectric, the bare- $\mathrm{AlO}_{\mathrm{x}} \mathrm{film}$, and the SAM, respectively), which yields values between approximately 1.7 and $2.1 \mu \mathrm{F} / \mathrm{cm}^{2}$ for the SAM, depending on the set of plasma parameters for which the cal-

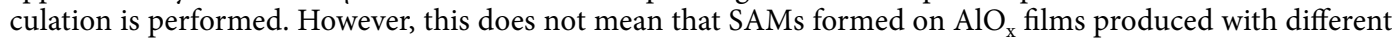
plasma parameters have different capacitances, but merely reflects the uncertainty in the measured capacitances combined with the fact that the influence of variations in the SAM capacitance on the total capacitance is very small. Assuming that the molecules employed for the SAM ( $n$-tetradecylphosphonic acid) have an alkyl-chain length of $1.9 \mathrm{~nm}$, as reported previously ${ }^{13,31}$, and that the molecules in the SAM have a tilt angle of $20-30^{\circ}$ with respect to the surface normal ${ }^{13}$, this corresponds to a permittivity between approximately 3.1 and 4.3 for the $n$-tetradecylphosphonic acid SAMs, which is larger by about 25 to $75 \%$ than the value of 2.5 that was reported previously for $n$-octadecyltrichlorosilane $\mathrm{SAMs}^{67}$. Whether this difference is systematic or not, and if so, how this difference can be explained, is not known.

The results of the measurements of the current density through the hybrid $\mathrm{AlO}_{\mathrm{x}} / \mathrm{SAM}$ dielectric are summarized in Fig. 4b. As can be seen, the leakage-current density through the hybrid $A_{1} O_{x} / S A M$ dielectrics is smaller by approximately an order of magnitude than the current density through the bare- $\mathrm{AlO}_{\mathrm{x}}$ dielectrics, regardless of the plasma parameters. For a plasma power of $200 \mathrm{~W}$ and a duration of $60 \mathrm{~s}$, the leakage-current density through the hybrid $\mathrm{AlO}_{\mathrm{x}} / \mathrm{SAM}$ dielectric drops below $10^{-6} \mathrm{~A} / \mathrm{cm}^{2}$. While this confirms the beneficial effect of the SAM in improving the insulating properties of the gate dielectric for low-power organic TFTs, the results in Fig. $4 \mathrm{~b}$ also clearly demonstrate the critical importance of providing an optimized $\mathrm{AlO}_{\mathrm{x}}$ film, even when complementing it with a SAM.

Organic TFTs with bare-AIO ${ }_{x}$ and hybrid $\mathrm{AlO}_{\mathrm{x}} / \mathrm{SAM}$ gate dielectrics. On the same substrates as the capacitors discussed above, we also fabricated bottom-gate, top-contact DNTT TFTs with either a bare- $\mathrm{AlO}_{\mathrm{x}}$ or a hybrid $\mathrm{AlO}_{\mathrm{x}} / \mathrm{SAM}$ gate dielectric produced using the same fifteen combinations of plasma power and duration as discussed above. Figure 5 shows the measured transfer characteristics and gate currents of TFTs fabricated with three of these plasma-parameter combinations; the complete set of results is shown in Figs. S3 and S4.

One observation from Figs. 5 and S3 is that a plasma power of $10 \mathrm{~W}$ is insufficient to suppress the gate-leakage current to an acceptable level, regardless of the plasma duration and regardless of whether or not the $\mathrm{AlO}_{\mathrm{x}}$ is complemented by a SAM. The minimum plasma power required to obtain $\mathrm{AlO}_{\mathrm{x}}$ films with sufficient thickness and sufficient quality to limit the gate current to $10^{-11} \mathrm{~A}$ over the range of gate-source voltages considered here $(0$ to $-3 \mathrm{~V})$ is $50 \mathrm{~W}$. For a plasma power in the range of 100 to $200 \mathrm{~W}$, both the bare- $\mathrm{AlO}_{\mathrm{x}}$ and the hybrid $\mathrm{AlO}_{\mathrm{x}} /$ SAM gate dielectric are able to provide gate currents not exceeding $10^{-11} \mathrm{~A}$ and on/off current ratios of $10^{6}$. The optimum plasma duration for this range of plasma power is dictated by whether or not the $\mathrm{AlO}_{\mathrm{x}}$ is complemented by a SAM: For the bare- $\mathrm{AlO}_{\mathrm{x}}$ gate dielectric, the optimum plasma duration is $\geq 300 \mathrm{~s}$, whereas for the hybrid $\mathrm{AlO}_{\mathrm{x}} / \mathrm{SAM}$ gate dielectric, the optimum plasma duration is in the range of 30 to $60 \mathrm{~s}$ (for a plasma power ranging from 100 to $200 \mathrm{~W}$ ).

In Fig. 6a, the effective charge-carrier mobility extracted from the measured transfer characteristics of the DNTT TFTs with a bare- $\mathrm{AlO}_{\mathrm{x}}$ gate dielectric is plotted as a function of the plasma power and the plasma duration. As can be seen, the carrier mobility of these TFTs is rather small, between 0.1 and $0.6 \mathrm{~cm}^{2} / \mathrm{Vs}$, which is possibly related to charge trapping and the formation of Fröhlich polarons, due to the fact that the organic semiconductor is in direct contact with the aluminum oxide ${ }^{64,68}$. 

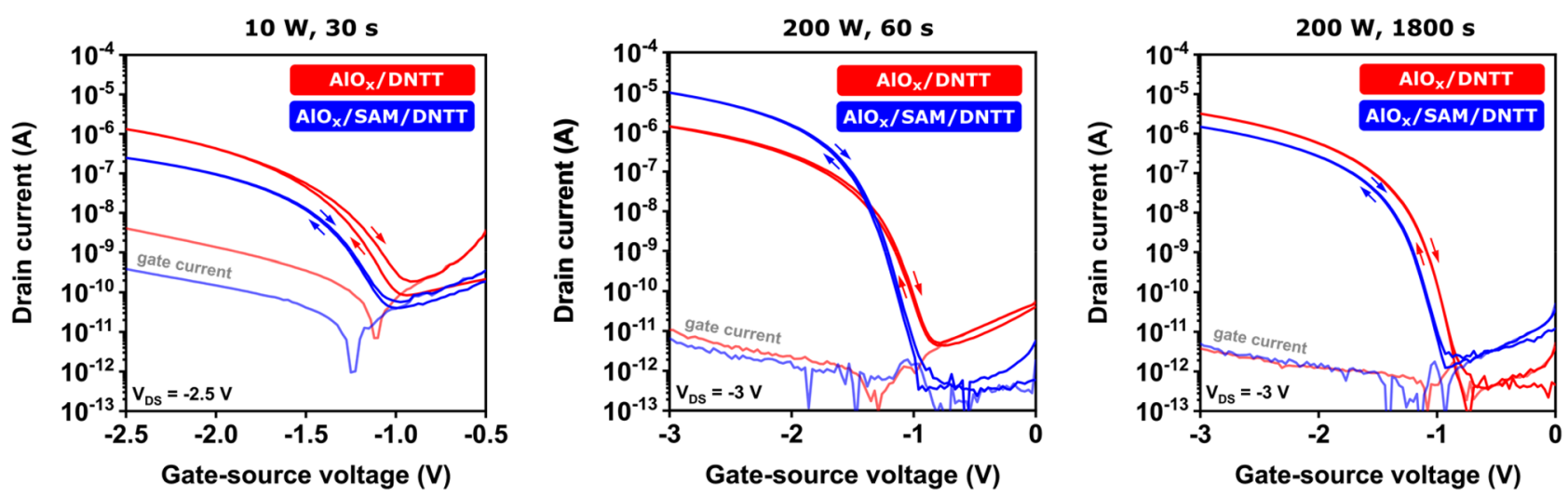

Figure 5. Transfer characteristics and gate currents of DNTT TFTs fabricated using either a bare-AlO gate dielectric (red curves) or a hybrid $\mathrm{AlO}_{\mathrm{x}} / \mathrm{SAM}$ gate dielectric (blue curves) for three combinations of plasma power and plasma duration. (Fig. S3 shows the complete set of results.) The TFTs have a channel length of $20 \mu \mathrm{m}$ and a channel width of $100 \mu \mathrm{m}$.
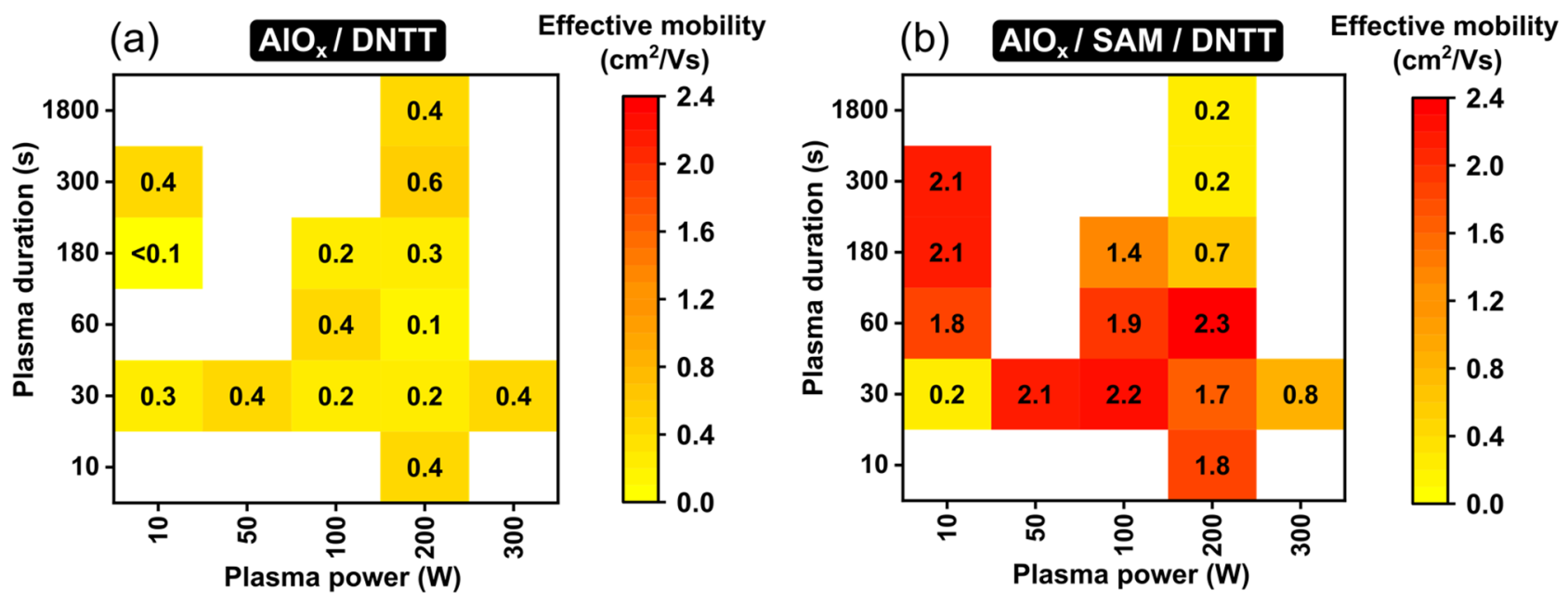

Figure 6. Effective charge-carrier mobilities extracted from the measured transfer characteristics of DNTT TFTs fabricated using either a bare- $\mathrm{AlO}_{\mathrm{x}}$ gate dielectric (a) or a hybrid $\mathrm{AlO}_{\mathrm{x}} / \mathrm{SAM}$ gate dielectric (b) as a function of plasma power and plasma duration.

The dependence of the carrier mobility of the TFTs with a hybrid $\mathrm{AlO}_{\mathrm{x}} / \mathrm{SAM}$ gate dielectric on the plasma parameters is summarized in Fig. 6b. The beneficial contribution of the SAM, in providing a hydrophobic surface with a greatly reduced density of water-related trap sites and effective screening of the organic-semiconductor film from the high-permittivity oxide, leads to notably larger carrier mobilities of up to $2.3 \mathrm{~cm}^{2} / \mathrm{Vs}$. Closer inspection of Fig. $6 \mathrm{~b}$ shows that carrier mobilities of approximately $2 \mathrm{~cm}^{2} / \mathrm{Vs}$ are obtained along a track from the upper left to the lower right corner of the graph, i.e., from low-power/long-duration to high-power/shortduration combinations. For parameter combinations outside of this corridor, the carrier mobilities are notably smaller, as small as $0.2 \mathrm{~cm}^{2} / \mathrm{Vs}$. The reasons for this distinctive parameter-dependence pattern will be elucidated in the following section.

Surface properties. The performance of field-effect transistors in general and of organic TFTs in particular is greatly dependent on the properties of the interface between the semiconductor and the gate dielectric ${ }^{69}$. In the case of bottom-gate TFTs, as considered here, this highlights the critical importance of the properties of the gate-dielectric surface. We have thus measured the surface energy and the surface roughness of the bare- $\mathrm{AlO}_{\mathrm{x}}$ and the hybrid $\mathrm{AlO}_{\mathrm{x}} / \mathrm{SAM}$ dielectrics for each of the fifteen combinations of plasma power and plasma duration discussed above.

The surface energies of both the bare- $\mathrm{AlO}_{\mathrm{x}}$ and the hybrid $\mathrm{AlO}_{\mathrm{x}} / \mathrm{SAM}$ dielectrics show only very small variations and no systematic dependence on the plasma parameters (see Fig. S7). The surface energy of the bare- $\mathrm{AlO}_{\mathrm{x}}$ dielectric varies between 61 and $71 \mathrm{~mJ} / \mathrm{m}^{2}$, and that of the hybrid $\mathrm{AlO}_{\mathrm{x}} / \mathrm{SAM}$ dielectric between 23 and $26 \mathrm{~mJ} /$ $\mathrm{m}^{2}$, similar to previous reports ${ }^{38,43}$.

The surface roughness, on the other hand, shows a clear correlation with the plasma parameters. Prior to the plasma-oxidation process, the vacuum-deposited aluminum has a root-mean-square (RMS) surface roughness of $0.9 \mathrm{~nm}^{53}$. After the plasma-oxidation process, the RMS surface roughness of the bare $\mathrm{AlO}_{\mathrm{x}}$ ranges from 0.34 to 
(a)

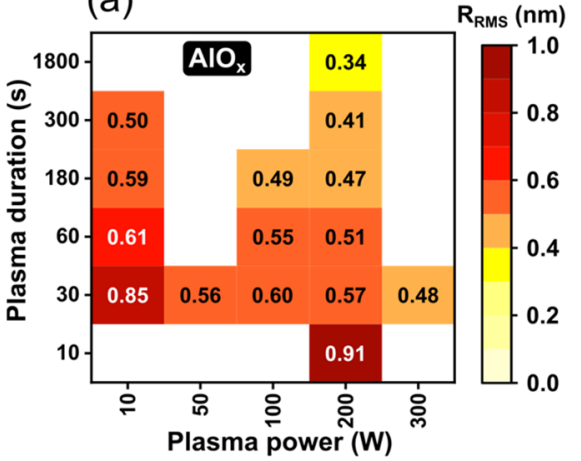

(c)

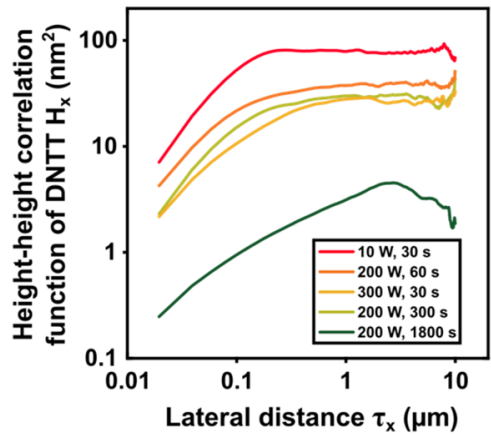

(d)

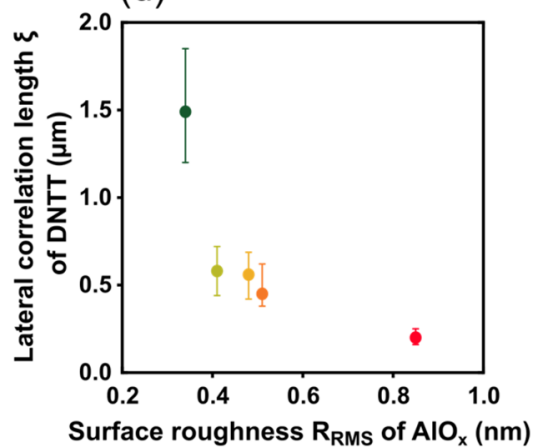

(b)
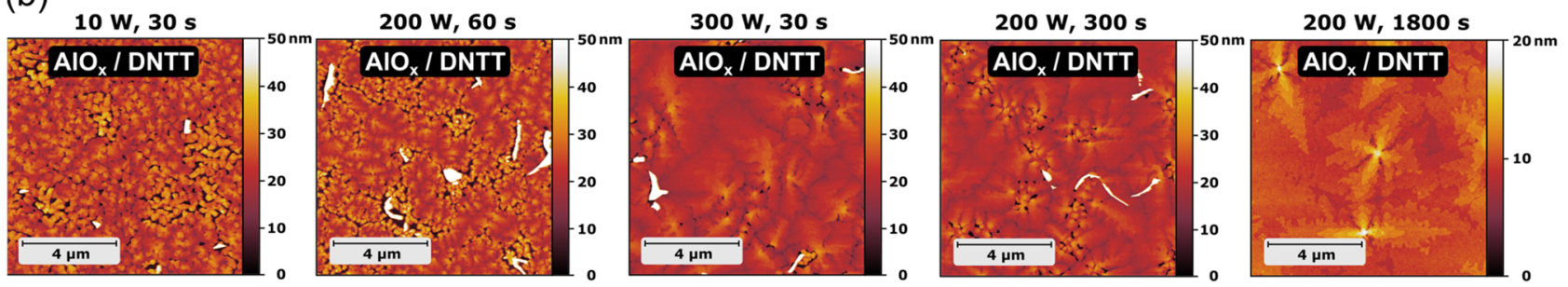

Figure 7. (a) Root-mean-square surface roughness of bare- $\mathrm{AlO}_{\mathrm{x}}$ dielectrics as a function of plasma power and plasma duration. (b) AFM images of DNTT films deposited onto bare- $\mathrm{AlO}_{\mathrm{x}}$ dielectrics for five combinations of plasma power and plasma duration. (c) Height-height correlation functions (HHCF) of DNTT films deposited onto bare- $\mathrm{AlO}_{\mathrm{x}}$ dielectrics for the same five combinations of plasma power and plasma duration. (d) Lateral correlation length $\xi$ of the DNTT films as a function of the surface roughness of the bare- $\mathrm{AlO}_{\mathrm{x}}$ dielectric.

$0.91 \mathrm{~nm}$, depending on the plasma parameters (shown in Fig. 7a). The general trend seen in Fig. 7a is that higher plasma power and longer plasma duration lead to smoother $\mathrm{AlO}_{\mathrm{x}}$ films. Given the difference between the RMS surface roughness of the aluminum prior to plasma oxidation $(0.9 \mathrm{~nm})$ and the RMS surface roughness of the plasma-grown $\mathrm{AlO}_{\mathrm{x}}(0.34$ to $0.91 \mathrm{~nm})$, it appears that the plasma-oxidation process smoothens the surface, most prominently for sufficiently high plasma powers and sufficiently long durations. This effect was not observed in our previous study ${ }^{53}$, in which we measured an almost identical RMS surface roughness of $0.9 \mathrm{~nm}$ for both the vacuum-deposited aluminum and the dielectric. However, in this previous study we did not explore the use of high plasma powers or long plasma durations, which might explain why no smoothening was observed.

The degree of the surface roughness of the dielectric affects the properties of the organic-semiconductor film deposited onto it ${ }^{53}$. When DNTT is deposited onto a smooth dielectric, the DNTT film exhibits a pronounced terrace-like structure, whereas deposition onto a rough dielectric results in a notably smaller terrace size. Qualitatively, this can already be seen in the AFM images in Fig. 7b, which show the morphology of DNTT deposited onto bare- $\mathrm{AlO}_{\mathrm{x}}$ dielectrics produced using different plasma parameters.

To evaluate the DNTT thin-film morphology in a quantitative manner, we have applied height-height correlation functions (HHCF), calculated from the AFM data using the following equation ${ }^{70}$ :

$$
\mathrm{H}_{\mathrm{x}}\left(\tau_{\mathrm{x}}\right)=\frac{1}{\mathrm{~N}(\mathrm{M}-\mathrm{m})} \sum_{\mathrm{l}=1}^{\mathrm{N}} \sum_{\mathrm{n}=1}^{\mathrm{M}-\mathrm{m}}\left(\mathrm{z}_{\mathrm{n}+\mathrm{m}, \mathrm{l}}-\mathrm{z}_{\mathrm{n}, \mathrm{l}}\right)^{2}
$$

where $\mathrm{N}$ and $\mathrm{M}$ are the number of measured rows and columns, $\mathrm{z}$ is the height of a measurement point, $\Delta \mathrm{x}$ is the sampling interval along the $\mathrm{x}$ direction, $\mathrm{m}$ an integer $(0 \leq \mathrm{m} \leq \mathrm{M})$, and $\tau_{\mathrm{x}}$ is the lateral distance $\left(\tau_{\mathrm{x}}=\mathrm{m} \Delta \mathrm{x}\right)$.

The HHCF has two distinct regimes, as seen in Fig. 7c: over short lateral distances, the heights are correlated and the HHCF increases linearly with distance. Over long distances, the heights are uncorrelated and the $\mathrm{HHCF}$ saturates at a value proportional to $2 \mathrm{R}_{\mathrm{RMS}}{ }^{271}$. The lateral distance at which the crossover between the two regimes occurs is the lateral correlation length $\xi$. In Fig. 7d, the lateral correlation length determined for each of the DNTT films deposited onto bare $\mathrm{AlO}_{\mathrm{x}}$ (Fig. 7b) is plotted as a function of the RMS surface roughness of the $\mathrm{AlO}_{\mathrm{x}}$. As can be seen, the lateral correlation length of the DNTT films shows a monotonic dependence on the $\mathrm{AlO}_{\mathrm{x}}$ surface roughness, increasing from $0.2 \mathrm{~nm}$ for the largest surface roughness to $1.5 \mathrm{~nm}$ for the smoothest surface. However, these trends are not reflected in the measured charge-carrier mobilities of the TFTs in which these bare- $\mathrm{AlO}_{\mathrm{x}}$ films serve as the gate dielectric (Fig. 6a), since the carrier mobility in these DNTT films is greatly suppressed, presumably by charge trapping and polaronic effects resulting from the close proximity of the DNTT and the aluminum oxide.

The RMS surface roughness of the hybrid $\mathrm{AlO}_{\mathrm{x}} / \mathrm{SAM}$ dielectrics as a function of plasma power and duration is shown in Fig. 8a. Comparing Fig. 7a and Fig. 8a shows that the functionalization of the $\mathrm{AlO}_{\mathrm{x}}$ surface with the SAM has no measurable effect on the roughness, i.e., the SAM covers the $\mathrm{AlO}_{\mathrm{x}}$ surface in a conformal manner, as expected. The extent to which the carrier mobility of the TFTs with the hybrid $\mathrm{AlO}_{\mathrm{x}} / \mathrm{SAM}$ dielectric correlates 
(a)

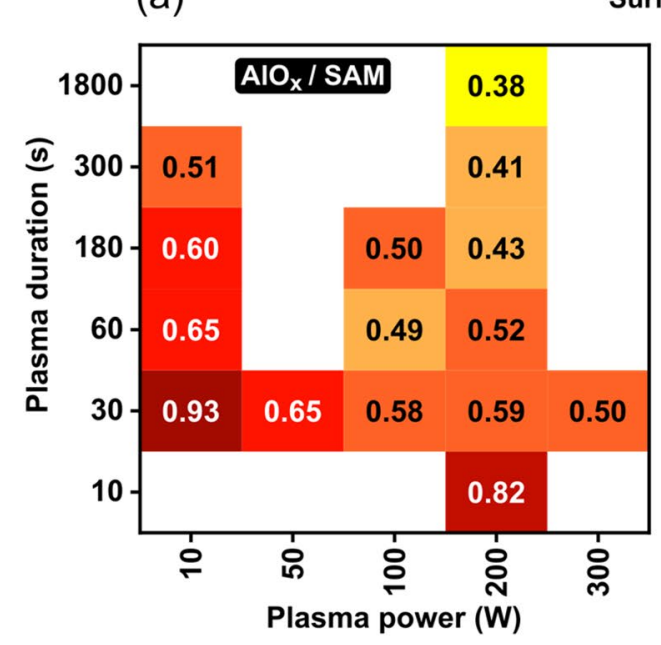

(b) $10 \mathrm{w}, 30 \mathrm{~s}$

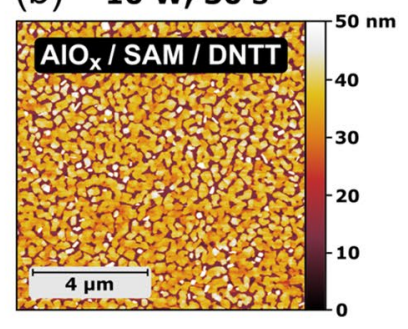

(d) $200 \mathrm{w}, 1800 \mathrm{~s}$

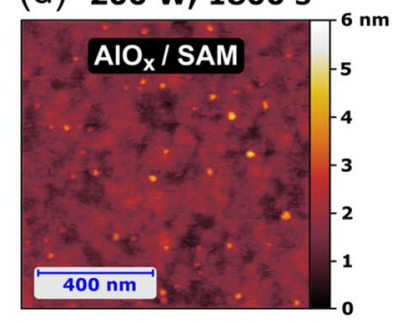

(c) $200 \mathrm{w}, 60 \mathrm{~s}$

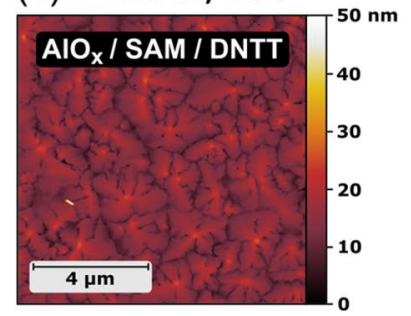

(e) $200 \mathrm{w}, 1800 \mathrm{~s}$

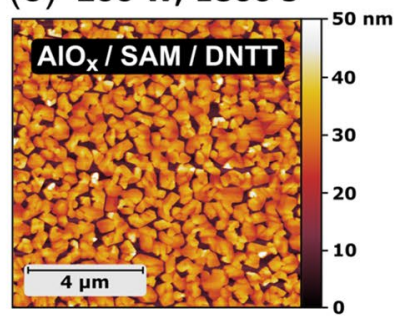

Figure 8. (a) Root-mean-square surface roughness of hybrid $\mathrm{AlO}_{\mathrm{x}} / \mathrm{SAM}$ dielectrics as a function of plasma power and plasma duration. (b-e) AFM images of representative morphologies on the indicated surfaces with the indicated plasma parameters.

with its surface roughness can be seen by comparing Fig. 6b and Fig. $8 \mathrm{a}$ (see also Fig. S5 where these graphs are reproduced and the carrier mobility is plotted as a function of the RMS surface roughness): the largest RMS surface roughness $(0.93 \mathrm{~nm}$; obtained with low plasma power/short duration; indicated in grey in Fig. S5) leads to a disordered DNTT film with small grains (Fig. 8 b) that shows a very small carrier mobility $\left(0.2 \mathrm{~cm}^{2} / \mathrm{Vs}\right.$ ), as expected ${ }^{53}$. The largest carrier mobilities $\left(\geq 2 \mathrm{~cm}^{2} / \mathrm{Vs}\right)$ are obtained only when the RMS surface roughness is below approximately $0.65 \mathrm{~nm}$ (indicated in green in Fig. S5), so that the DNTT morphology shows a pronounced terrace-like structure (Fig. 8c); this is also in line with expectations. On the other hand, the smallest RMS surface roughness $(0.38 \mathrm{~nm}$; obtained with medium power/long duration; indicated in blue in Fig. S5) does not lead to the largest carrier mobility, as one might have expected, but instead to a very small mobility $\left(0.2 \mathrm{~cm}^{2} / \mathrm{Vs}\right)$. The reason for this anomaly is revealed by the AFM image of this dielectric (Fig. 8d), in which a large density of small, tall features can be seen protruding from the surface. These features do not significantly contribute to the calculated RMS surface roughness, but they influence the DNTT morphology in an unfavorable manner, as seen in Fig. 8e. The specifics of these tall features are unknown, but the fact that they appear only for long plasma durations ( $\geq 300 \mathrm{~s}$ ) suggests that they mark some form of mechanical damage created on the $\mathrm{AlO}_{\mathrm{x}}$ surface by prolonged plasma exposure. AFM images of DNTT films deposited onto hybrid $\mathrm{AlO}_{\mathrm{x}} / \mathrm{SAM}$ dielectrics for all fifteen combinations of plasma power and plasma duration are collected in Fig. S6.

Organic TFTs and complementary circuits on flexible plastic substrates. The process described above is suitable for the fabrication of organic TFTs on flexible substrates, such as plastics ${ }^{15}$ and paper ${ }^{23}$. Figure 9a shows a photograph of organic TFTs and circuits fabricated on a polyethylene naphthalate (PEN) substrate. Based on the findings reported above, a plasma power of $200 \mathrm{~W}$ and a plasma duration of $60 \mathrm{~s}$ were chosen for the preparation of the aluminum oxide as part of the gate dielectric. Figure $9 \mathrm{~b}$ and $\mathrm{c}$ show the measured transfer and output characteristics of a DNTT TFT, indicating a carrier mobility of $2 \mathrm{~cm}^{2} / \mathrm{Vs}$, an on/off current ratio of $10^{7}$ and a maximum gate current of $10^{-11} \mathrm{~A}$. Results of a bias-stress measurement performed on such a TFT are summarized in Fig. S8.

Figure 10 shows the transfer and output characteristics of $\mathrm{p}$-channel and $\mathrm{n}$-channel organic TFTs and the transfer characteristics of a complementary inverter fabricated on flexible PEN. The $\mathrm{AlO}_{\mathrm{x}}$ film was again prepared using a plasma power of $200 \mathrm{~W}$ and a duration of $60 \mathrm{~s}$. The organic semiconductors that were used to fabricate these devices are 2,7-diphenyl[1] benzothieno[3,2-b]benzothiophene (DPh-BTBT) ${ }^{15,72,73}$ for the $\mathrm{p}$-channel TFTs and N,N'-bis(2,2,3,3,4,4,4-heptafluorobutyl)-1,7-dicyano-perylene-(3,4:9,10)-tetracarboxylic diimide (PTCDI$(\mathrm{CN})_{2}-\left(\mathrm{CH}_{2} \mathrm{C}_{3} \mathrm{~F}_{7}\right)_{2}$; Polyera ActivInk N1100 $)^{74,75}$ for the n-channel TFTs. The TFTs have effective charge-carrier mobilities of $0.6 \mathrm{~cm}^{2} / \mathrm{Vs}$ (DPh-BTBT) and $0.2 \mathrm{~cm}^{2} / \mathrm{Vs}(\mathrm{N} 1100)$. At a supply voltage of $2 \mathrm{~V}$, the complementary inverter has a maximum small-signal gain of 135 and a minimum noise margin of $89 \%$ of half the supply voltage, calculated according to Ref. ${ }^{76}$. To our knowledge, this is the largest minimum noise margin reported to date for an organic complementary inverter fabricated on a flexible substrate (see Table 1).

\section{Conclusion}

Ultrathin, high-capacitance hybrid gate dielectrics based on oxygen-plasma-grown aluminum oxide films in combination with an alkylphosphonic acid SAM are useful for the realization of low-voltage organic TFTs. Depending on the plasma power and the duration of the plasma exposure, the thickness of the plasma-grown $\mathrm{AlO}_{\mathrm{x}}$ films can be tuned to values between approximately 4.3 and $7.3 \mathrm{~nm}$. The lower limit of the range of accessible 
(a)

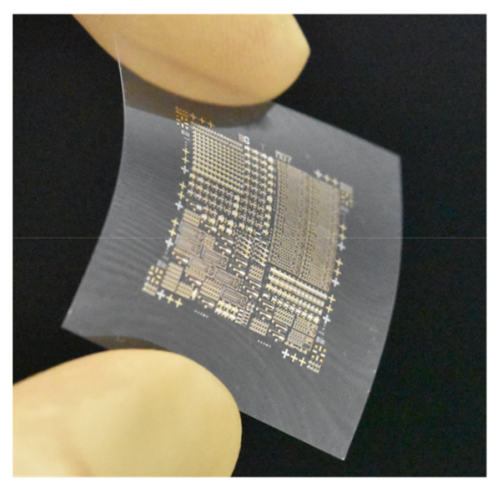

(b)

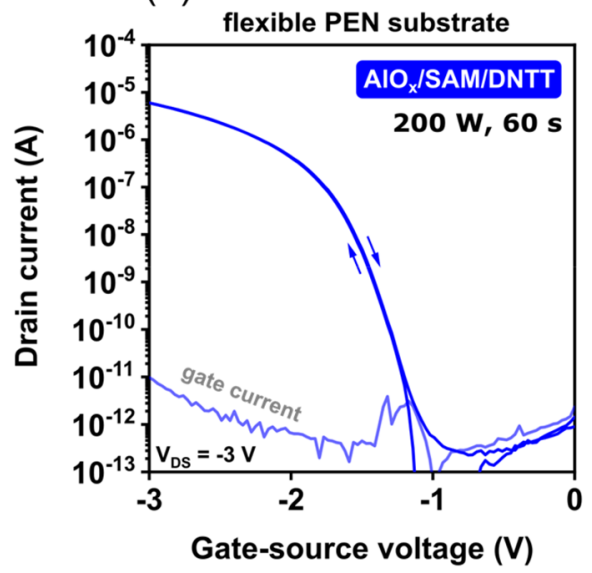

(c)

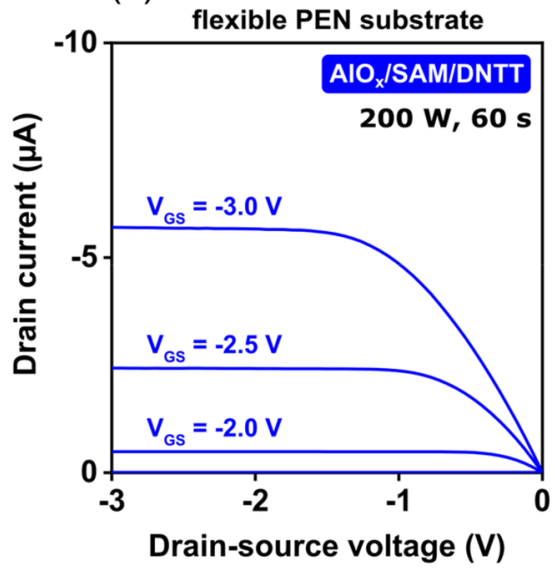

Figure 9. (a) Photograph of organic TFTs and circuits fabricated on a flexible polyethylene naphthalte (PEN) substrate. (b) Measured transfer and (c) output characteristics of a DNTT TFT with a channel length of $20 \mu \mathrm{m}$ and a channel width of $100 \mu \mathrm{m}$ on flexible PEN. The effective charge-carrier mobility is $2 \mathrm{~cm}^{2} / \mathrm{Vs}$.

(a)

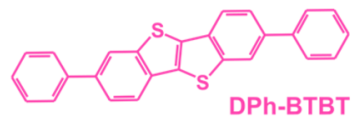

(c)

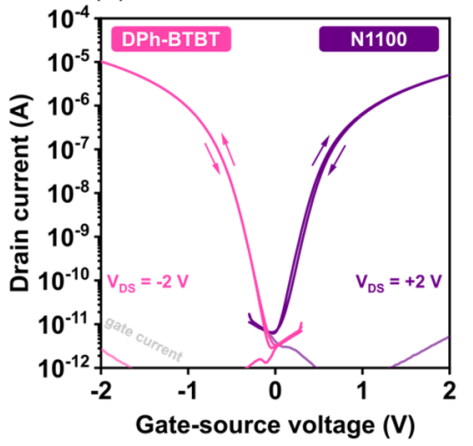

(b)

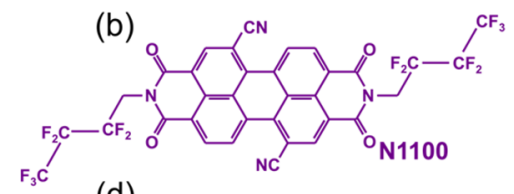

(d)

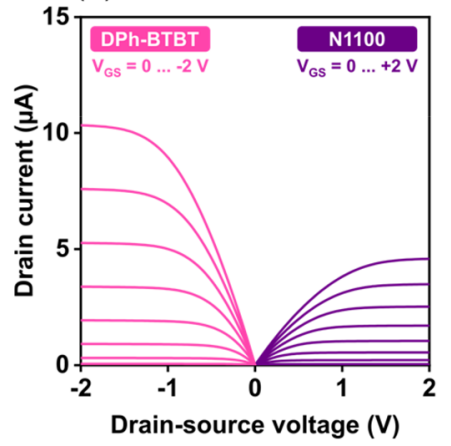

(e)

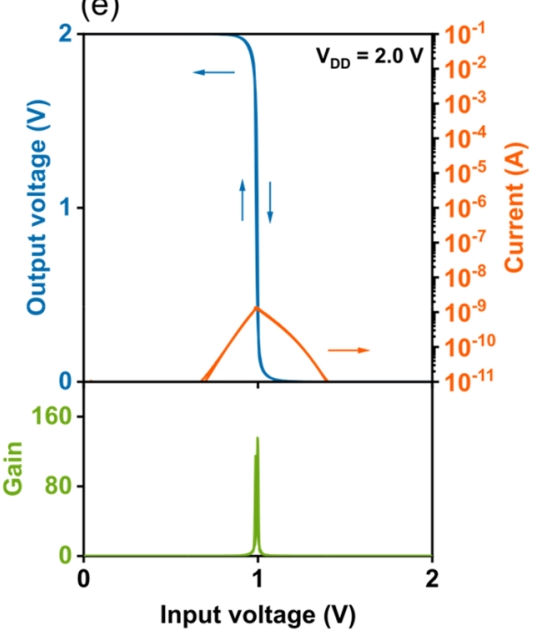

Figure 10. Chemical structures of the organic semiconductors (a) 2,7-diphenyl[1]benzothieno[3,2-b] benzothiophene (DPh-BTBT) and (b) (PTCDI- $(\mathrm{CN})_{2}-\left(\mathrm{CH}_{2} \mathrm{C}_{3} \mathrm{~F}_{7}\right)_{2}$; Polyera ActivInk N1100). (c) Transfer and (d) output characteristics of a DPh-BTBT p-channel TFT and an N1100 n-channel TFT. The TFTs have a channel length of $40 \mu \mathrm{m}$ and a channel width of $1000 \mu \mathrm{m}$. (e) Transfer characteristics of a complementary inverter based on a DPh-BTBT p-channel TFT and an N1100 n-channel TFT fabricated on a flexible PEN substrate.

\begin{tabular}{|c|c|c|c|c|c|c|c|c|}
\hline Reference & Substrate material & $\begin{array}{l}\text { Gate-dielectric } \\
\text { material }\end{array}$ & $\begin{array}{l}\text { Gate-dielectric } \\
\text { capacitance }(\mathrm{nF} / \\
\left.\mathrm{cm}^{2}\right)\end{array}$ & Small-signal gain & Supply voltage (V) & $\begin{array}{l}\text { Voltage- } \\
\text { normalized gain } \\
\left(\mathrm{V}^{-1}\right)\end{array}$ & $\begin{array}{l}\text { Noise margin (of } \\
\left.V_{\mathrm{DD}} / 2\right)(\%)\end{array}$ & $\begin{array}{l}\text { Measurement } \\
\text { ambient }\end{array}$ \\
\hline 76 & Glass & $\mathrm{AlO}_{\mathrm{x}} / \mathrm{SAM}$ & 700 & 435 & 2 & 218 & 80 & Air \\
\hline 78 & Glass & Anodic $\mathrm{Ta}_{2} \mathrm{O}_{5}$ & 140 & 500 & 5 & 100 & 84 & Vacuum \\
\hline 79 & Glass & $\mathrm{AlO}_{\mathrm{x}} / \mathrm{SAM}$ & 700 & 120 & 3 & 40 & 80 & Air \\
\hline 80 & Glass & $\mathrm{AlO}_{\mathrm{x}} / \mathrm{SAM}$ & 700 & 376 & 3 & 125 & 80 & Air \\
\hline 81 & Glass & $\mathrm{Al}_{2} \mathrm{O}_{3} / \mathrm{TMSC}$ & 65 & 500 & 4 & 125 & 92.5 & Glove box \\
\hline 81 & Glass & $\mathrm{Al}_{2} \mathrm{O}_{3} / \mathrm{TMSC}$ & 65 & 740 & 5 & 148 & 85 & Glove box \\
\hline 15 & Flexible PEN & $\mathrm{AlO}_{\mathrm{x}} / \mathrm{SAM}$ & 700 & 180 & 1 & 180 & 84 & Air \\
\hline 82 & Flexible PEN & $\mathrm{Al}_{2} \mathrm{O}_{3} / \mathrm{PS}$ & 26.5 & 170 & 5 & 34 & 80 & Glove box \\
\hline 83 & Flexible PEN & CVD polymer & 70 & 118 & 3 & 39 & 80 & Glove box \\
\hline This work & Flexible PEN & $\mathrm{AlO}_{\mathrm{x}} / \mathrm{SAM}$ & 700 & 135 & 2 & 68 & 89 & Air \\
\hline
\end{tabular}

Table 1. Summary of organic complementary inverters with a small-signal gain greater than 100 and a minimum noise margin of at least $80 \%$ of half the supply voltage $\left(\mathrm{V}_{\mathrm{DD}}\right)$. 
thicknesses is dictated by the thickness of the native aluminum oxide (approximately $3 \mathrm{~nm}$ ) that forms spontaneously when the substrates are exposed to ambient air prior to the plasma-oxidation process, while the upper boundary is set by the inherently self-limiting oxidation kinetics of aluminum oxide. The relative permittivity of the oxygen-plasma-grown $\mathrm{AlO}_{\mathrm{x}}$ films is approximately $8 \pm 0.2$, and the capacitance of the bare- $\mathrm{AlO}_{\mathrm{x}}$ films thus falls into the range from 1 to $1.6 \mu \mathrm{F} / \mathrm{cm}^{2}$. By allowing a high-quality monolayer of an alkylphosphonic acid with medium alkyl-chain length to self-assemble on the freshly grown $\mathrm{AlO}_{\mathrm{x}}$ surface, a hybrid $\mathrm{AlO}_{\mathrm{x}} / \mathrm{SAM}$ dielectric is obtained, the capacitance of which varies between 0.7 and $0.8 \mu \mathrm{F} / \mathrm{cm}^{2}$, depending on the plasma parameters. The leakage-current density through the hybrid $\mathrm{AlO}_{\mathrm{x}} / \mathrm{SAM}$ dielectrics was found to be smaller by about an order of magnitude than the current density through bare- $\mathrm{AlO}_{\mathrm{x}}$ dielectrics. For example, for a plasma power of $200 \mathrm{~W}$ and a plasma duration of $60 \mathrm{~s}$, the leakage-current density through the hybrid $\mathrm{AlO}_{\mathrm{x}} / \mathrm{SAM}$ dielectric drops below $10^{-6} \mathrm{~A} / \mathrm{cm}^{2}$ at voltages of $\pm 3 \mathrm{~V}$, confirming the beneficial effect of the SAM in improving the insulating properties of the gate dielectric for low-power organic TFTs.

The effective charge-carrier mobility of DNTT TFTs with a bare- $\mathrm{AlO}_{\mathrm{x}}$ gate dielectric is no greater than 0.6 $\mathrm{cm}^{2} / \mathrm{Vs}$, and shows little dependence on the plasma parameters. In TFTs with a hybrid $\mathrm{AlO}_{\mathrm{x}} / \mathrm{SAM}$ dielectric, carrier mobilities ranging from 1.8 to $2.3 \mathrm{~cm}^{2} / \mathrm{Vs}$ were obtained for a number of favorable combinations of plasma power and plasma duration that produce $\mathrm{AlO}_{\mathrm{x}}$ films with small surface roughness and thus promote the formation of high-quality SAMs and well-ordered DNTT films on these dielectrics. An important finding is that while the properties of the plasma-grown $\mathrm{AlO}_{\mathrm{x}}$ films can be tuned over a certain range without negatively affecting the charge-transport properties in the organic-semiconductor films deposited onto them, this is only true as long as the plasma power and the plasma duration do not exceed values beyond which the quality of the plasma-grown oxide films suffers from surface damage. The largest carrier mobility equaling $2.3 \mathrm{~cm}^{2} / \mathrm{Vs}$ was obtained for a plasma-parameter combination of $200 \mathrm{~W}$ and $60 \mathrm{~s}$.

This work highlights the properties of oxygen-plasma-grown aluminum oxide films as part of high-capacitance gate dielectrics in low-voltage organic transistors and identifies the optimum process parameters for their fabrication.

\section{Experimental section}

Fabrication of capacitors and TFTs on silicon substrates. Metal-insulator-metal capacitors and inverted staggered (bottom-gate, top-contact) TFTs were fabricated on silicon substrates coated with $100-\mu \mathrm{m}$-thick thermally grown silicon dioxide. For the bottom electrode of the capacitors and the gate electrode of the TFTs, aluminum with a thickness of $30 \mathrm{~nm}$ and a root-mean-square surface roughness of less than $1 \mathrm{~nm}$ (measured by $\mathrm{AFM}^{53}$ ) was deposited by thermal evaporation in vacuum with a rate of about $20 \AA$ s. $\mathrm{AlO}_{\mathrm{x}}$ films were produced by plasma oxidation in an Oxford Instruments ProLab100 Cobra system in pure oxygen with a partial pressure of 0.01 mbar using the capacitively coupled plasma mode with an excitation frequency of $13.56 \mathrm{MHz}$. We fabricated substrates with fifteen different combinations of plasma power (ranging from 10 to $300 \mathrm{~W}$ ) and duration (ranging from 10 to $1800 \mathrm{~s}$ ). After the plasma oxidation, each substrate was cleaved into two halves. One half was immersed into a 2-propanol solution of $n$-tetradecylphosphonic acid (PCI Synthesis, Newburyport, MA, USA) to form a self-assembled monolayer and hence a hybrid $\mathrm{AlO}_{\mathrm{x}} / \mathrm{SAM}$ dielectric. The other half remained without SAM (bare- $\mathrm{AlO}_{\mathrm{x}}$ dielectric). Onto both halves of each substrate, the small-molecule semiconductor dinaphtho[2,3-b:2',3'-f] thieno[3,2-b]thiophene (DNTT; Sigma Aldrich) was deposited by thermal sublimation in vacuum with a deposition rate of $0.3 \AA / \mathrm{s}$ and with a nominal thickness of $25 \mathrm{~nm}$. During the DNTT deposition, the substrate was held at a constant temperature of $80{ }^{\circ} \mathrm{C}$. For the top electrode of the capacitors and the source/drain contacts of the TFTs, gold with a thickness of $30 \mathrm{~nm}$ was deposited by thermal evaporation in vacuum with a rate of $0.3 \AA / \mathrm{s}$. The metals and the DNTT were patterned using polyimide shadow masks (CADiLAC Laser, Hilpoltstein, Germany). The capacitors have an area of $200 \mu \mathrm{m} \times 200 \mu \mathrm{m}$. The TFTs have a channel length of $20 \mu \mathrm{m}$ and a channel width of $100 \mu \mathrm{m}$. For each of the fifteen combinations of plasma power and plasma duration, capacitors and TFTs were fabricated on the same substrate to minimize the effects of unintentional parameter variations.

Fabrication of TFTs and complementary inverters on flexible substrates. Polyethylene naphthalate (PEN) with a thickness of $125 \mu \mathrm{m}$ (Teonex Q65 PEN; kindly provided by William A. MacDonald, DuPont Teijin Films, Wilton, U.K.) was used as a flexible substrate. Aluminum gate electrodes (thickness: $30 \mathrm{~nm}$ ) and $\mathrm{AlO}_{\mathrm{x}}$ films (plasma power: $200 \mathrm{~W}$, plasma duration: $60 \mathrm{~s}$ ) were prepared as on the silicon substrates. For DNTT TFTs, an $n$-tetradecylphosphonic acid SAM was prepared as on the silicon substrates. For TFTs based on the semiconductors 2,7-diphenyl[1]benzothieno[3,2-b]benzothiophene (DPh-BTBT; Sigma Aldrich) and N,N'bis $\left(2,2,3,3,4,4,4\right.$-heptafluorobutyl)-1,7-dicyano-perylene-(3,4:9,10)-tetracarboxylic diimide (PTCDI-(CN) $2_{2}^{-}$ $\left(\mathrm{CH}_{2} \mathrm{C}_{3} \mathrm{~F}_{7}\right)_{2}$; ActivInk N1100; Polyera Corp., Skokie, IL, U.S.A.), a mixed SAM composed of $25 \% n$-octadecylphosphonic acid and 75\% 12,12,13,13,14,14,15,15,16,16,17,17,18,18,18-pentadecafluoroctadecylphosphonic acid (synthesized by Matthias Schlörholz, Heidelberg, Germany) was prepared ${ }^{15}$. Source and drain contacts were prepared as on the silicon substrates. The DNTT TFTs have a channel length of $20 \mu \mathrm{m}$ and a channel width of $100 \mu \mathrm{m}$. The DPh-BTBT and N1100 TFTs have a channel length of $40 \mu \mathrm{m}$ and a channel width of $1000 \mu \mathrm{m}$.

TEM characterization. The TEM specimen was prepared on a silicon substrate by repeating the deposition of 30-nm-thick aluminum and the plasma-induced oxidation of its surface five times, each time with a different combination of plasma power and plasma duration. Preparing all five $\mathrm{AlO}_{\mathrm{x}}$ films on the same substrate, rather than on five separate substrates, was helpful in minimizing the time required for thinning the specimen in preparation for cross-sectional microscopy. The TEM specimen was fabricated by conventional focused ion beam (FIB) lift-out using a Thermo Fisher Scientific FEI Scios DualBeam instrument equipped with a gallium source. 
A platinum strip was deposited to protect the films from ion-beam damage. A lamella with a size of approximately $20 \mu \mathrm{m} \times 10 \mu \mathrm{m}$ was released from the substrate and glued to a copper TEM lift-out grid. The lamella was then thinned to a thickness of less than $100 \mathrm{~nm}$ using an acceleration voltage of $30 \mathrm{kV}$ and an ion current of initially $500 \mathrm{pA}$ that was successively decreased to $100 \mathrm{pA}$. Afterwards, the lamella was cleaned using a low-voltage cleaning step with an acceleration voltage of $5 \mathrm{kV}$ and an ion current of $48 \mathrm{pA}$ to remove gallium-beam damage. The TEM image was recorded in bright-field (BF) mode using a Philips CM-200 FEG TEM operated with an acceleration voltage of $200 \mathrm{kV}$.

Electrical characterization. All electrical measurements were performed in ambient air at room temperature under yellow laboratory light. The capacitance measurements were performed using a Hameg HM8118 LCR meter by applying an alternating voltage with an amplitude of $0.2 \mathrm{~V}$ and a frequency of $1 \mathrm{kHz}$. The currentvoltage measurements were performed using an Agilent 4156C Semiconductor Parameter Analyzer and the measurement software "SweepMe!" (https://sweep-me.net). The effective charge-carrier mobility was calculated by fitting the following equation to the measured transfer curve:

$$
\mu_{\mathrm{eff}}=\frac{2 \mathrm{~L}}{\mathrm{C}_{\mathrm{diel}} \mathrm{W}}\left(\frac{\partial \sqrt{\mathrm{I}_{\mathrm{D}}}}{\partial \mathrm{V}_{\mathrm{GS}}}\right)^{2}
$$

where $I_{D}$ is the drain current, $V_{G S}$ the gate-source voltage, $C_{\text {diel }}$ the unit-area capacitance of the gate dielectric, $\mathrm{L}$ the channel length and $\mathrm{W}$ the channel width.

Surface characterization. AFM images were recorded in air using a Bruker Dimension Icon Atomic Force Microscope in peak force tapping mode (for the DNTT films) or in tapping mode (for the dielectrics). Data processing was performed using the AFM analysis software Gwyddion. Static contact-angle measurements were performed using a Krüss contact angle measurement system. The contact angles of water and hexadecane on the $\mathrm{AlO}_{\mathrm{x}}$ dielectrics were measured immediately after the plasma treatment of the aluminum films. The contact angles of water and hexadecane on the $\mathrm{AlO}_{\mathrm{x}} / \mathrm{SAM}$ hybrid dielectrics were measured immediately after the SAM treatment. The surface energies were calculated using the Owens-Wendt $\operatorname{method}^{77}$.

Received: 6 November 2020; Accepted: 28 February 2021

Published online: 18 March 2021

\section{References}

1. Noda, M. et al. An OTFT-driven rollable OLED display. J. Soc. Inf. Disp. 19, 316-322 (2011).

2. Someya, T. et al. Conformable, flexible, large-area networks of pressure and thermal sensors with organic transistor active matrixes. Proc. Natl. Acad. Sci. 102, 12321 (2005).

3. Sekitani, T., Zschieschang, U., Klauk, H. \& Someya, T. Flexible organic transistors and circuits with extreme bending stability. Nat. Mater. 9, 1015-1022 (2010).

4. Wang, B. et al. High-k Gate dielectrics for emerging flexible and stretchable electronics. Chem. Rev. 118, 5690-5754 (2018).

5. Rogers, J. A. et al. Paper-like electronic displays: Large-area rubber- stamped plastic sheets of electronics and microencapsulated electrophoretic inks. Proc. Natl. Acad. Sci. 98, 4835-4840 (2001).

6. Yoon, M.-H., Yan, H., Facchetti, A. \& Marks, T. J. Low-voltage organic field-effect transistors and inverters enabled by ultrathin cross-linked polymers as gate dielectrics. J. Am. Chem. Soc. 127, 10388-10395 (2005).

7. Yang, S. Y., Kim, S. H., Shin, K., Jeon, H. \& Park, C. E. Low-voltage pentacene field-effect transistors with ultrathin polymer gate dielectrics. Appl. Phys. Lett. 88, 173507 (2006).

8. Koo, J. B. et al. Low-voltage and high-gain pentacene inverters with plasma-enhanced atomic-layer-deposited gate dielectrics. Appl. Phys. Lett. 89, 033511 (2006).

9. Chang, M. F., Lee, P. T., McAlister, S. P. \& Chin, A. Low subthreshold swing HfLaO/pentacene organic thin-film transistors. IEEE Electron. Dev. Lett. 29, 215-217 (2008).

10. Yoon, M.-H., Facchetti, A. \& Marks, T. J. $\sigma-\pi$ molecular dielectric multilayers for low-voltage organic thin-film transistors. Proc. Natl. Acad. Sci. 102, 4678 (2005).

11. DiBenedetto, S. A., Frattarelli, D., Ratner, M. A., Facchetti, A. \& Marks, T. J. Vapor phase self-assembly of molecular gate dielectrics for thin film transistors. J. Am. Chem. Soc. 130, 7528-7529 (2008).

12. Kelley, T. W. et al. High-performance OTFTs using surface-modified alumina dielectrics. J. Phys. Chem. B 107, 5877-5881 (2003).

13. Klauk, H., Zschieschang, U., Pflaum, J. \& Halik, M. Ultralow-power organic complementary circuits. Nature 445, 745-748 (2007).

14. Jinno, H. et al. Low operating voltage organic transistors and circuits with anodic titanium oxide and phosphonic acid selfassembled monolayer dielectrics. Org. Electron. 40, 58-64 (2017).

15. Zschieschang, U., Bader, V. P. \& Klauk, H. Below-one-volt organic thin-film transistors with large on/off current ratios. Org. Electron. 49, 179-186 (2017).

16. Haase, K. et al. Solution shearing of a high-capacitance polymer dielectric for low-voltage organic transistors. Adv. Electron. Mater. 5, 1900067 (2019).

17. Halik, M. et al. Low-voltage organic transistors with an amorphous molecular gate dielectric. Nature 431, 963-966 (2004).

18. Xiong, W., Guo, Y., Zschieschang, U., Klauk, H. \& Murmann, B. A 3-V, 6-bit C-2C digital-to-analog converter using complementary organic thin-film transistors on glass. IEEE J. Solid-State Circuits 45, 1380-1388 (2010).

19. Abdinia, S. et al. Organic CMOS line drivers on foil. IEEE J. Disp. Technol. 11, 564-569 (2015).

20. Stucchi, E., Dell'Erba, G., Colpani, P., Kim, Y.-H. \& Caironi, M. Low-voltage, printed, all-polymer integrated circuits employing a low-leakage and high-yield polymer dielectric. Adv. Electron. Mater. 4, 1800340 (2018).

21. Zschieschang, U. \& Klauk, H. Low-voltage organic transistors with steep subthreshold slope fabricated on commercially available paper. Org. Electron. 25, 340-344 (2015).

22. Lei, T. et al. Biocompatible and totally disintegrable semiconducting polymer for ultrathin and ultralightweight transient electronics. Proc. Natl. Acad. Sci. 114, 5107-5112 (2017). 
23. Kraft, U. et al. Low-voltage, high-frequency organic transistors and unipolar and complementary ring oscillators on paper. Adv. Electron. Mater. 5, 1800453 (2019).

24. Borchert, J. W. et al. Small contact resistance and high-frequency operation of flexible low-voltage inverted coplanar organic transistors. Nat. Commun. 10, 1119 (2019).

25. Aghamohammadi, M. et al. Threshold-voltage shifts in organic transistors due to self-assembled monolayers at the dielectric: Evidence for electronic coupling and dipolar effects. ACS Appl. Mater. Interfaces 7, 22775-22785 (2015).

26. Majewski, L. A., Schroeder, R., Voigt, M. \& Grell, M. High performance organic transistors on cheap, commercial substrates. J. Phys. D 37, 3367-3372 (2004).

27. Majewski, L. A., Schroeder, R. \& Grell, M. One volt organic transistor. Adv. Mater. 17, 192-196 (2005).

28. Kaltenbrunner, M. et al. An ultra-lightweight design for imperceptible plastic electronics. Nature 499, 458-463 (2013).

29. Gupta, S. et al. Ozone oxidation methods for aluminum oxide formation: Application to low-voltage organic transistors. Org. Electron. 21, 132-137 (2015).

30. Chinnam, K. C., Gupta, S. \& Gleskova, H. Aluminium oxide prepared by UV/ozone exposure for low-voltage organic thin-film transistors. J. Non. Cryst. Solids 358, 2512-2515 (2012).

31. Jedaa, A. et al. The impact of self-assembled monolayer thickness in hybrid gate dielectrics for organic thin-film transistors. Org. Electron. 10, 1442-1447 (2009).

32. Kwon, J., Lee, Y., Jo, Y. \& Jung, S. Fabrication of ultrathin low-voltage-driven printed organic circuits with anodized gate islands. Org. Electron. 62, 77-81 (2018).

33. Yogev, S. et al. Fermi level pinning by gap states in organic semiconductors. Phys. Rev. Lett. 110, 036803 (2013).

34. Borchert, J. W. et al. Flexible low-voltage high-frequency organic thin-film transistors. Sci. Adv. 6, 5156 (2020).

35. Leshanskaya, L. I. et al. Towards understanding the origin of the hysteresis effects and threshold voltage shift in organic field-effect transistors based on the electrochemically grown $\mathrm{AlO}_{\mathrm{x}}$ dielectric. Thin Solid Films 649, 7-11 (2018).

36. Ulman, A. Formation and structure of self-assembled monolayers. Chem. Rev. 96, 1533-1554 (1996).

37. Luschtinetz, R. et al. Adsorption of phosphonic and ethylphosphonic acid on aluminum oxide surfaces. Surf. Sci. 602, 1347-1359 (2008).

38. Kraft, U. et al. Fluoroalkylphosphonic acid self-assembled monolayer gate dielectrics for threshold-voltage control in low-voltage organic thin-film transistors. J. Mater. Chem. 20, 6416 (2010).

39. Acton, O. et al. Simultaneous modification of bottom-contact electrode and dielectric surfaces for organic thin-film transistors through single-component spin-cast monolayers. Adv. Funct. Mater. 21, 1476-1488 (2011).

40. Acharya, R., Peng, B., Chan, P. K. L., Schmitz, G. \& Klauk, H. Achieving ultralow turn-on voltages in organic thin-film transistors: Investigating fluoroalkylphosphonic acid self-assembled monolayer hybrid dielectrics. ACS Appl. Mater. Interfaces 11, 27104-27111 (2019).

41. Hirata, I. et al. High-resolution spatial control of the threshold voltage of organic transistors by microcontact printing of alkyl and fluoroalkylphosphonic acid self-assembled monolayers. Org. Electron. 26, 239-244 (2015).

42. Fukuda, K. et al. Effects of the alkyl chain length in phosphonic acid self-assembled monolayer gate dielectrics on the performance and stability of low-voltage organic thin-film transistors. Appl. Phys. Lett. 95, 203301 (2009).

43. Acton, O. et al. Dielectric surface-controlled low-voltage organic transistors via n-alkyl phosphonic acid self-assembled monolayers on high-k metal oxide. ACS Appl. Mater. Interfaces 2, 511-520 (2010).

44. Hannah, S. et al. Interplay between vacuum-grown monolayers of alkylphosphonic acids and the performance of organic transistors based on Dinaphtho[2,3-b:2',3'-f]thieno[3,2-b]thiophene. ACS Appl. Mater. Interfaces 8, 25405-25414 (2016).

45. Gleskova, H., Gupta, S. \& Šutta, P. Structural changes in vapour-assembled n-octylphosphonic acid monolayer with post-deposition annealing: Correlation with bias-induced transistor instability. Org. Electron. 14, 3000-3006 (2013).

46. Gupta, S. \& Gleskova, H. Dry growth of n-octylphosphonic acid monolayer for low-voltage organic thin-film transistors. Org. Electron. 14, 354-361 (2013).

47. Hauffman, T., Hubin, A. \& Terryn, H. Study of the self-assembling of n-octylphosphonic acid layers on aluminum oxide from ethanolic solutions. Surf. Interface Anal. 45, 1435-1440 (2013).

48. Bauer, T. et al. Phosphonate-and carboxylate-based self-assembled monolayers for organic devices: A theoretical study of surface binding on aluminum oxide with experimental support. ACS Appl. Mater. Interfaces 5, 6073 (2013).

49. Yamamoto, T. \& Takimiya, K. Facile synthesis of highly $\pi$-extended heteroarenes, dinaphtho[2,3-b: 2',3'-f]chalcogenopheno[3,2-b] chalcogenophenes, and their application to field-effect transistors. J. Am. Chem. Soc. 129, 2224-2225 (2007).

50. Zschieschang, U. et al. Dinaphtho[2,3-b:2',3'-f]thieno[3,2-b]thiophene (DNTT) thin-film transistors with improved performance and stability. Org. Electron. 12, 1370-1375 (2011).

51. Milvich, J. et al. Flexible low-voltage organic phototransistors based on air-stable dinaphtho[2,3-b:2',3'-f] thieno[3,2-b]thiophene (DNTT). Org. Electron. 20, 63-68 (2015).

52. Evertsson, J. et al. The thickness of native oxides on aluminum alloys and single crystals. Appl. Surf. Sci. 349, 826-832 (2015).

53. Geiger, M. et al. Effect of the degree of the gate-dielectric surface roughness on the performance of bottom-gate organic thin-film transistors. Adv. Mater. Interfaces 7, 1902145 (2020).

54. Harman, A. K., Ninomiya, S. \& Adachi, S. Optical constants of sapphire $\left(\alpha-\mathrm{Al}_{2} \mathrm{O}_{3}\right)$ single crystals. J. Appl. Phys. 76, 8032-8036 (1994).

55. Groner, M. D., Fabreguette, F. H., Elam, J. W. \& George, S. M. Low-temperature $\mathrm{Al}_{2} \mathrm{O}_{3}$ atomic layer deposition. Chem. Mater. 16, 639-645 (2004).

56. Acharya, J., Wilt, J., Liu, B. \& Wu, J. Probing the dielectric properties of ultrathin $\mathrm{Al} / \mathrm{Al}_{2} \mathrm{O}_{3} / \mathrm{Al}$ trilayers fabricated using in situ sputtering and atomic layer deposition. ACS Appl. Mater. Interfaces 10, 3112-3120 (2018).

57. Cabrera, N. \& Mott, N. F. Theory of the oxidation of metals. Rep. Prog. Phys. 12, 163-184 (1949).

58. Cai, N., Zhou, G., Müller, K. \& Starr, D. E. Tuning the limiting thickness of a thin oxide layer on $\mathrm{Al}(111)$ with oxygen gas pressure. Phys. Rev. Lett. 107, 035502 (2011).

59. Baran, J. D., Grönbeck, H. \& Hellman, A. Mechanism for limiting thickness of thin oxide films on aluminum. Phys. Rev. Lett. 112, 146103 (2014).

60. Kim, K. D. \& Song, C. K. Low voltage pentacene thin film transistors employing a self-grown metal-oxide as a gate dielectric. Appl. Phys. Lett. 88, 233508 (2006).

61. Kang, H., Han, K.-K., Park, J.-E. \& Lee, H. H. High mobility, low voltage polymer transistor. Org. Electron. 8, 460-464 (2007).

62. Chua, L.-L. et al. General observation of n-type field-effect behaviour in organic semiconductors. Nature 434, 194-199 (2005).

63. Kettner, M., Zhou, M., Brill, J., Blom, P. W. M. \& Weitz, R. T. Complete suppression of bias-induced threshold voltage shift below $273 \mathrm{~K}$ in solution-processed high-performance organic transistors. ACS Appl. Mater. Interfaces 10, 35449-35454 (2018).

64. Hulea, I. N. et al. Tunable Fröhlich polarons in organic single-crystal transistors. Nat. Mater. 5, 982-986 (2006).

65. Chung, Y. et al. Controlling electric dipoles in nanodielectrics and its applications for enabling air-stable n-channel organic transistors. Nano Lett. 11, 1161-1165 (2011). 
66. Pernstich, K. P. et al. Threshold voltage shift in organic field effect transistors by dipole monolayers on the gate insulator. J. Appl. Phys. 96, 6431-6438 (2004).

67. Fontaine, P. et al. Octadecyltrichlorosilane monolayers as ultrathin gate insulating films in metal-insulator-semiconductor devices. Appl. Phys. Lett. 62, 2256-2258 (1993).

68. Li, J., Du, J., Xu, J., Chan, H. L. W. \& Yan, F. The influence of gate dielectrics on a high-mobility n-type conjugated polymer in organic thin-film transistors. Appl. Phys. Lett. 100, 033301 (2012).

69. Chen, H., Zhang, W., Li, M., He, G. \& Guo, X. Interface engineering in organic field-effect transistors: Principles, applications, and perspectives. Chem. Rev. 120, 2879-2949 (2020).

70. Klapetek, P., Nečas, D., Anderson, C., Necas, D. \& Anderson, C. Gwyddion User Guide (Springer, 2013).

71. Gredig, T., Silverstein, E. A. \& Byrne, M. P. Height-height correlation function to determine grain size in iron phthalocyanine thin films. J. Phys. Conf. Ser. 417, 012069 (2013).

72. Takimiya, K. et al. 2,7-Diphenyl[1]benzothieno[3,2-b]benzothiophene, a new organic semiconductor for air-stable organic fieldeffect transistors with mobilities up to $2.0 \mathrm{~cm}^{2} \mathrm{~V}^{-1} \mathrm{~s}^{-1}$. J. Am. Chem. Soc. 128, 12604-12605 (2006).

73. Moon, H., Cho, H., Kim, M., Takimiya, K. \& Yoo, S. Towards colorless transparent organic transistors: Potential of benzothieno[3,2b]benzothiophene-based wide-Gap semiconductors. Adv. Mater. 26, 3105-3110 (2014).

74. Jones, B. A. et al. High-mobility air-stable n-type semiconductors with processing versatility: Dicyanoperylene-3,4:9,10bis(dicarboximides). Angew. Chem. Int. Ed. 43, 6363-6366 (2004).

75. Soeda, J. et al. High electron mobility in air for $\mathrm{N}, \mathrm{N}^{\prime}-1 \mathrm{H}, 1 \mathrm{H}$ - perfluorobutyldicyanoperylene carboxydi-imide solution-crystallized thin-film transistors on hydrophobic surfaces. Adv. Mater. 23, 3681-3685 (2011).

76. Zschieschang, U. et al. Mixed self-assembled monolayer gate dielectrics for continuous threshold voltage control in organic transistors and circuits. Adv. Mater. 22, 4489-4493 (2010).

77. Owens, D. K. \& Wendt, R. C. Estimation of the surface free energy of polymers. J. Appl. Polym. Sci. 13, 1741-1747 (1969).

78. Tatemichi, S., Ichikawa, M., Kato, S., Koyama, T. \& Taniguchi, Y. Low-voltage, high-gain, and high-mobility organic complementary inverters based on N, N'-ditridecyl-3,4,9,10-perylenetetracarboxylic diimide and pentacene. Phys. Stat. Sol. RRL 2, 47-49 (2008).

79. Zschieschang, U., Halik, M. \& Klauk, H. Microcontact-printed self-assembled monolayers as ultrathin gate dielectrics in organic thin-film transistors and complementary circuits. Langmuir 24, 1665 (2008).

80. Martens, S. C., Zschieschang, U., Wadepohl, H., Klauk, H. \& Gade, L. H. Tetrachlorinated tetraazaperopyrenes (TAPPs): Highly fluorescent dyes and semiconductors for air-stable organic n-channel transistors and complementary circuits. Chem. Eur. J. 18, 3498 (2012).

81. Petritz, A. et al. Cellulose-derivative-based gate dielectric for high-performance organic complementary inverters. Adv. Mater. 27, 7645 (2015).

82. Zhang, X., Potscavage, W. J., Choi, S. \& Kippelen, B. Low-voltage flexible organic complementary inverters with high noise margin and high dc gain. Appl. Phys. Lett. 94, 043312 (2009).

83. Seong, H. et al. Organic inverters: A low-voltage organic complementary inverter with high operation stability and flexibility using an ultrathin iCVD polymer dielectric and a hybrid encapsulation layer. Adv. Electron. Mater. 2, 1500385 (2016).

\section{Acknowledgements}

This work is partially funded by the German Research Foundation (DFG) under the Grants KL 2223/6-2 (SPP FFlexCom), KL 2223/7-1, and INST 35/1429-1 (SFB 1249).

\section{Author contributions}

M.G., H.K. and R.A. devised the experimental details of the study. M.G., U.Z. and R.A. fabricated the devices and samples and performed electrical measurements and surface characterization. M.H, T.R. and J.W. supervised the Oxford Instruments ProLab100 Cobra system and gave technical assistance. H.S. and G.S. performed the TEM characterization and gave technical assistance. M.G., H.K. and R.A. wrote the manuscript. R.T.W., G.S., H.K., G.S. and R.A. supervised the project. All the authors discussed the results and contributed to the development of the final manuscript.

\section{Funding}

Open Access funding enabled and organized by Projekt DEAL.

\section{Competing interests}

The authors declare no competing interests.

\section{Additional information}

Supplementary Information The online version contains supplementary material available at https://doi.org/ 10.1038/s41598-021-85517-7.

Correspondence and requests for materials should be addressed to M.G. or R.A.

Reprints and permissions information is available at www.nature.com/reprints.

Publisher's note Springer Nature remains neutral with regard to jurisdictional claims in published maps and institutional affiliations.

(c) (i) Open Access This article is licensed under a Creative Commons Attribution 4.0 International License, which permits use, sharing, adaptation, distribution and reproduction in any medium or format, as long as you give appropriate credit to the original author(s) and the source, provide a link to the Creative Commons licence, and indicate if changes were made. The images or other third party material in this article are included in the article's Creative Commons licence, unless indicated otherwise in a credit line to the material. If material is not included in the article's Creative Commons licence and your intended use is not permitted by statutory regulation or exceeds the permitted use, you will need to obtain permission directly from the copyright holder. To view a copy of this licence, visit http://creativecommons.org/licenses/by/4.0/.

(c) The Author(s) 2021 